\title{
Cost Optimization of Steel-concrete Composite Floor Systems with Castellated Steel Beams
}

\author{
Ali Kaveh ${ }^{1 *}$, Amir Fakoor ${ }^{1}$ \\ ${ }^{1}$ School of Civil Engineering, Iran University of Science and Technology, Narmak, Tehran, P.O. Box 16846-13114, Iran \\ * Corresponding author, e-mail: alikaveh@iust.ac.ir
}

Received: 12 September 2020, Accepted: 15 November 2020, Published online: 20 November 2020

\begin{abstract}
Performance of cost optimization program of composite steel deck-slabs (DS) and supporting castellated beams (CB) consisting of interior beams, edge beams and girders is proposed in this paper. The program applies the vibrating particle system (VPS) metaheuristic algorithm, which imitates the free vibration of ideal one-story frame structures with viscous damping.

The program is also furnished with an advanced cost function, which takes into account both material and fabrication costs of all parts of the floor system. The effect of four major cost reduction procedures and additional cost-saving techniques are studied on the cost function. Considering various DS profiles, altering the dimensions of hexagonal openings, different number of floor divisions and choosing costlier DSs except the optimal deck are the major cost reduction procedures. Inclusion of partial composite action for CBs, infilling certain openings of CBs and applying camber are the supplementary economizing techniques. To realize the economy of LRFD method, a meticulous design theory of composite CBs in adherence with LRFD principles of AISC 360-16 specifications is applied to the formulation of the strength constraints. Due to excessive deflections and due emphasis on vibration control of CBs, we implement accurate design procedures for the formulation of the serviceability constraints. Performance and superiority of the proposed optimization program is validated by studying three distinct real-size design examples taken from the literatures.
\end{abstract}

\section{Keywords}

structural cost optimization, optimum design of steel floors, composite castellated steel beams, floor division number, partial composite action, meta-heuristic algorithm, Vierendeel mechanism, AISC-LRFD

\section{Introduction}

\subsection{General}

Metaheuristics are computational intelligence methods that explore and exploit the search space iteratively, in order to find near-optimal solutions. Metaheuristics as compared to analytical approaches, are not confined to convergence into local minima or require derivatives of the objective function and the constraints. They are therefore suitable methods for inherently large search spaces and numerous constraints of real-size multivariable design problems. For size optimization of structural design problems, metaheuristics have mostly been focused on the minimum weight design. However, only a small portion of these approaches deal with the minimum total cost [1].

\subsection{Application and aims}

A composite DS (i.e. deck-slab) is an assemblage of steel decks and concrete slab connected by steel anchors to a base of supporting steel framing which is an assembly of interior beams, edge beams and girders. The combination of composite DSs and perforated supporting beams produce a structurally resource efficient flooring system for a range of applications. This is considered to be a sustainable and economic construction method for structures with long span requirements as well as the best solution for structures with long open spaces, such as carparks, garages, industrial and warehouse facilities, schools, and hospitals [2].

The proposed program optimizes not only the cost of composite DSs which is not a difficult task, but also the cost of all supporting beams that are destined to be built as CBs (i.e., castellated beams). The program selects the solid-web I shaped members as a root beam of CBs intelligently, in such a way that the material cost of the predefined framing layout of a specific floor system turns out to be minimized. While this is the main concern of the majority of articles, our model also examines a number of procedures for further reduction of the total cost of the floor system. 


\subsection{Cost reduction procedures}

A steel deck acts as permanent formwork of the concrete. Not only does it provide a safe working platform and speed up the construction process, but also utilizes proper embossments to provide sufficient shear bond with the concrete so that the two materials act compositely together.

It is evident from Fig. 1 that combination of decking sheet thickness $\left(t_{d}\right)$ with three parameters regarding the deck ribs including the height $\left(h_{r}\right)$, average width $\left(w_{r}\right)$, and center to center distance $\left(d_{r}\right)$ in conjunction with total slab thickness $\left(t_{s}\right)$ together specify the variables for defining the geometry of a DS profile. As the first major cost reduction procedure, the program enables us to study the effect of dimensional variables of various DS profiles on the total cost by utilizing certain composite decks taken from fabricator catalogues.

The supporting steel beams could be chosen as either plain-webbed or perforated I shape sections. In comparison to the equivalent conventional plain-webbed beams, perforated beams offer many design and construction advantages while keeping the weight invariant. They provide a greater strong axis moment of inertia $\left(I_{x}\right)$, section modulus $\left(S_{x}\right)$ and depth-to-weight ratio. Thus the employment of perforated beams reduces the overall mass of the structure, resulting in lessened lateral design force and reduced foundation loads. Since the installation could run through their depth, they also decrease the overall height of the buildings which leads to more durable and economical construction method. Yet, these advantages come at the expense of more complex analysis and design procedures.

The two common types of perforated steel beams are beams with hexagonal openings, referred to as CBs and those with circular openings known as cellular beams. Fabrication of perforated beams is an important viewpoint as it affects the structural behavior and the cost of the final product. In contrast to $\mathrm{CBs}$, cellular beams require two cuts along their web centerline during the profile cutting fabrication procedure which leads to an increase in the fabrication cost and amount of material wastage (Fig. 2). Additionally, researchers have proved that CBs are also superior to cellular beams from the material cost point of view [3].

Cutting height $(h)$, cutting angle $(\theta)$, and horizontal cutting length $(e)$ define the dimensions of the hexagonal cutting of CBs which are illustrated in Fig. 2(a). The second major cost reduction procedure, intelligently find the optimal values of these variables within the corresponding admissible set in order to minimize the cost.

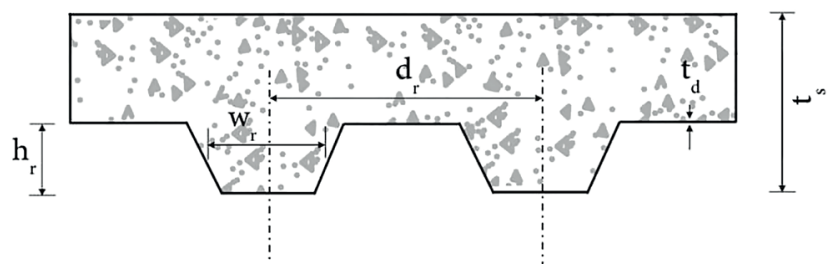

Fig. 1 Basic variables of composite steel deck-slab

(a)

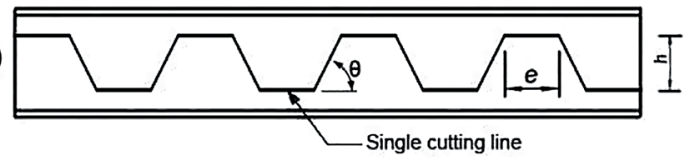

(b)

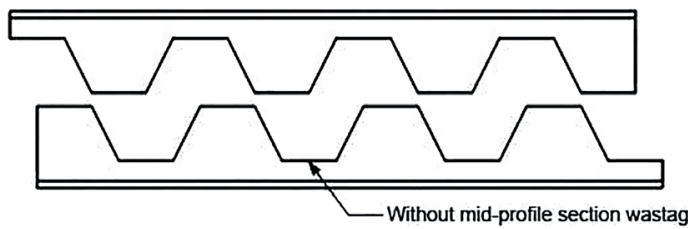

(c)

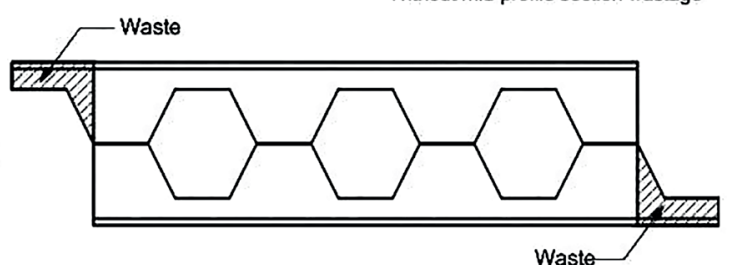

Fig. 2 Manufacturing and basic variables for fabrication of castellated steel beams

Participation of concrete in resisting the global shear reduces the Vierendeel moment in tees which is the merit of composite versus non-composite construction. The strength of stud anchors determine the ultimate strength of the composite section as full composite action is generally not the most economical solution to resist the required strength [4]. Therefore, in spite of the plethora of articles which either exclude the steel-concrete composite construction or merely consider the full composite action, our program facilitates the design of either fully or partially steel-concrete composite beams depending on the design parameters. These together with infilling certain holes and specifying camber are regarded as supplementary cost-saving techniques.

The third major cost reduction mechanism examines the possibility of lightening the CBs by increasing the composite action resulting from selecting costlier DSs. As the fourth major cost reduction mechanism, the model examines all possible floor division numbers incrementally and scrutinizes the results in order to find its optimal value.

\subsection{Survey of the pertinent literature}

Analytical and numerical optimization approaches have been conducted for cost minimization of concrete slab with conventional plain webbed beams. Adeli and Kim [5] 
formulated the optimal design of composite beams as a mixed integer-discrete nonlinear programming problem and solved the problem by a neural dynamics model. They showed that their patented cost optimization algorithm leads to substantial cost saving. Kaveh and Ahangaran [1] investigated the performance of social harmony search algorithm for cost optimization of composite beams. They illustrated good performance of their proposed algorithm for achieving minimum cost in least iteration. Klanšek and Kravanja [6] presented the cost optimization of composite floor systems and proved its capability by solving a numerical example. They implemented nonlinear programming for the purpose of optimization and formulated the constraints according to Eurocode 4. They presented a detailed objective function which took the complete structure's manufacturing costs into account. Poitras et al. [7] incorporated both mass and cost objective functions into the particle swarm optimization algorithm for minimizing the cost of composite floor systems whose components satisfy Canadian CSA S16 standard requirements. They evaluated different degrees of composite action and interestingly, results revealed an increase in the percentage of composite action is not always proportional to the drop in cost.

Utilizing perforated steel beams because of their numerous benefits is becoming more customary. However, less attention has been paid to optimal design of perforated steel beams. Tsavdaridis and D'Mello [8] studied the optimization of novel elliptically-based web openings for perforated steel beams. Kaveh and Shokohi [3] optimized simply supported non-composite castellated and cellular beams by the rules of the European standard. Kaveh and Ghafari [9] utilized Enhanced Colliding Body Optimization algorithm for cost optimization of composite floor systems with castellated beams. They also studied the effect of the number of floor divisions and compared the results of composite CBs with composite solid beams. They proved that utilizing CBs as compared to solid-webbed beams can reduce the cost up to $14 \%$.

\subsection{Objectives}

A state-of-the-art design theory of composite $\mathrm{CBs}$ in adherence with LRFD principals of 2016 version of AISC Specification for Structural Steel Buildings [4] (hereafter called AISC provisions) is applied for the first time for optimal design of composite CBs. Since web perforations reduce the stiffness of a member at openings, limit states of serviceability taken on increased importance.
Therefore, accurate design procedures for assuring functional capability of the floor systems are also incorporated into the program.

The principal object of this research is to put forward a reliable and comprehensive optimal design program of composite floor systems with castellated beams for application in practical purposes. The program minimizes both the material and fabrication cost of the composite floor systems.

An efficient meta-heuristic algorithm along with a number of cost reduction procedures are integrated to form an effective optimization program. These procedures involve inquiring into the effect of various steel deck profiles, finding the optimum dimensions of hexagonal castellation, finding the effect of floor division numbers and investigating the effect of selecting costlier DSs. Moreover, considering the partial composite action, infilling certain holes and imposing camber to $\mathrm{CBs}$ are supplementary economizing techniques.

\subsection{Outline}

This paper is divided into 4 sections: In Section 2.1 the design of composite castellated beam is outlined. In Section 2.2 statement of the optimal design problem is formulated. In Section 2.3, the implemented optimization algorithm is briefly described. In Section 3, the cost of three structural floor systems is optimized, and finally Section 4 concludes the paper.

\section{Methods}

\subsection{Design of composite castellated beams}

\subsubsection{General failure modes}

The behavior of composite CBs (i.e. castellated beams) is not similar to solid-web composite members due to the substantial number of web openings. We cannot, therefore, utilize classical methods of analysis and design for these intermediate structural components. In contrast to solid web members, the web openings necessitate the assessment of many additional failure modes in the design process. CBs are composed of tee sections and web posts which require pertinent strength limit states. Moreover, significant deformation due to bending and shear stresses as a result of web openings increases the complexity of the assessment of serviceability limit states.

The limit states that govern the design of composite CBs comprise: local buckling of tee components; flexural buckling of top tees and web posts; tensile yielding of bottom tees; plastic moment of tees; LTB of tees; interaction 
criteria of tees and posts; shear yielding and shear buckling of tees, gross section and posts; web post lateral instability together with deflection; and vibration.

The following describes a state-of-the-art design theory of composite CBs largely based on AISC Design Guide 31, Castellated and Cellular Beam Design [2], Design of Welded Structures [10] and additional research centering on lateral buckling of CBs [11]. The authors also completed the existing design theory by including the interaction criterion for web posts subjected to combined compression and flexure. Thus the design checks of both components of $\mathrm{CB}$, namely tees and posts, are simply be performed through beam-column interaction equations.

\subsubsection{Loads combinations}

In order to prevent composite $\mathrm{CBs}$ to reach their ultimate load carrying capacity, the design strength must be equal to or greater than the effects of factored load in the following load combinations [12]:

$L C_{1}=1.2 w_{D}+1.6 w_{L}$.

In regard to visually unacceptable deformations and other short term effects, the recommended load combination is:
$L C_{2}=w_{D}+w_{L}$,

where $w_{D}$ and $w_{L}$ are uniform dead load and live load, respectively.

\subsubsection{Design for anchorage to concrete}

The number of steel anchors required for full composite action, between the point of maximum positive moment and the point of zero moment is [4]:

$$
\begin{aligned}
& N_{s}=Q_{u} / Q_{n}= \\
& \min \left(0.85 f_{c}^{\prime} A_{c}, F_{y} A_{s}\right) /\left(0.5 A_{s a}\left(f_{c}^{\prime} E_{c}\right)^{0.5} \leq R_{g} R_{p} A_{s a} F_{u}\right),
\end{aligned}
$$

where $Q_{u}$ is the shear forces transferred by installed steel anchors and $Q_{n}$ is the nominal shear strength of one shear stud; $f_{c}^{\prime}$ is the compressive resistance of concrete; $A_{c}$ is the area of concrete slab within the effective width, $F_{y}$ is the minimum yield stress of steel, $A_{s}$ is the area of steel net section; $A_{s a}$ is the area of shear stud; $E_{c}$ is the modulus of elasticity of concrete; $R_{g}$ and $R_{p}$ respectively are the group and position effect factors of shear studs; $F_{u}$ is the minimum tensile strength of the shear studs.

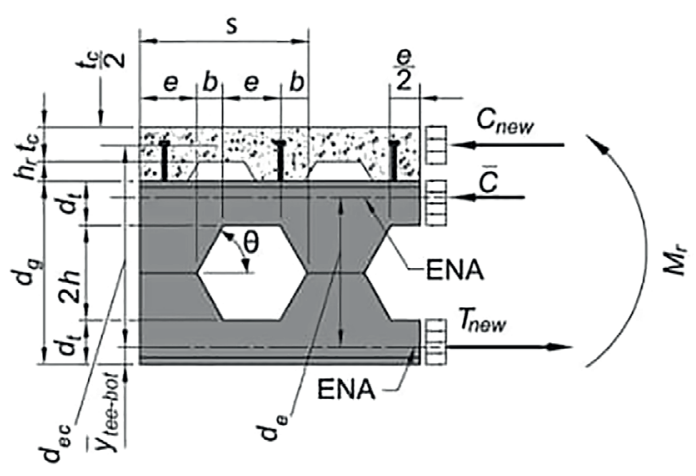

(b)

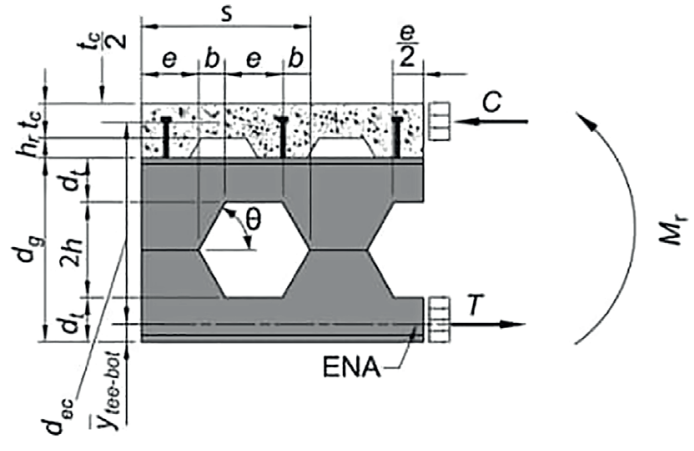

(a)

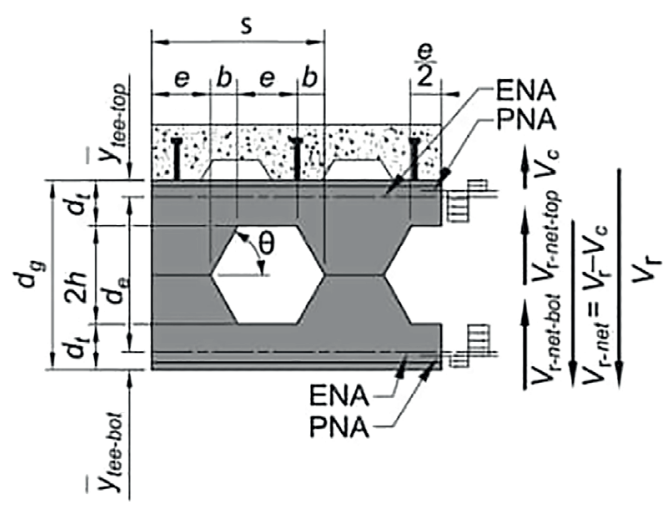

(c)

Fig. 3 Terminology of (a) calculating axial forces in full composite beams; (b) calculating axial forces in partially composite beams; and (c) calculating Vierendeel moments in composite beams 


\subsubsection{Vierendeel bending in composite CBs}

Vierendeel moment is a localized bending moment in the upper and lower tees developed from the passage of global shear force through the openings. The formation of plastic hinges at four areas in the portion of high shear forces in the vicinity of the openings may onset the Vierendeel failure mechanism.

\section{Calculation of axial forces in tee sections}

Firstly, it is assumed that there are sufficient studs at an opening under consideration to provide adequate amount of concrete such that the concrete flange carries all the compressive force and the bottom tee takes all the tensile force. Thus, if the beam at the specified opening is considered as full composite, the force $\left(\bar{C}_{i}\right)$ shown in Fig. 3(b) would vanish, and as depicted schematically in Fig. 3(a) the compressive force $\left(C_{i}\right)$ in the concrete would equate the tensile force $\left(T_{i}\right)$ in the bottom tee section and shall be calculated as follows [2]:

$$
T_{i}=C_{i}=\frac{M_{r(i)}}{d_{e c(i)}} \leq Q_{i},
$$

where $M_{r(i)}$ is the calculated global moment at the center of each opening; $d_{e c(i)}$ is the effective depth of the composite section which shall be determined in an iterative manner which for the first iteration shall be taken as $d_{e c(i)}=d_{g}-\bar{y}_{t b}+h_{r}+0.5 t_{c}$; Where $d_{g}$ is the depth of the CB; $\bar{y}_{t b}$ is the distance from the bottom fiber to the centroid of the bottom tee; $t_{c}$ is the depth of the concrete flange; and $i$ is the numerator of the web openings.

The actual depth of the concrete block $a_{(i)}$ resisting the compressive chord force shall be recalculated as:

$$
a_{(i)}=\frac{T_{i}}{0.85 f_{c}^{\prime} b_{e}} .
$$

The parameter $a_{(i)}$ must be replaced with the parameter $t_{c}$ iteratively until the convergence of the operation. As long as Eq. (4) is valid, the assumption that the $i$ th opening acts as fully composite is also valid and the concrete has the strength to resist the compressive chord force. Otherwise the partial composite action exists at that opening.

The total stud strength within the end of the beam and the intended opening is determined as:

$$
Q_{i}=q X_{i}=\left(\frac{N_{t} Q_{n}}{L}\right) X_{i},
$$

where $q$ is the average stud density; $X_{i}$ is the distance form the end of the beam to the center of the intended opening; $N_{t}$ is the total number of studs.
According to Fig. 3(b), if a section at the web openings due to insufficient composite action acts as partially composite, the supplementary compressive force that must be sustained by the top tees is calculated as follows:

$$
\bar{C}_{i}=d_{e}^{-1}\left(M_{r(i)}-d_{e c(i)} Q_{i}\right) \text {. }
$$

Hence, the revised tension force to be resisted by the bottom tees $T_{\text {i-new }}$ (Fig. 3(b)) shall be recalculated as:

$$
\begin{aligned}
T_{i-\text { new }} & =Q_{i}+\bar{C}_{i} \\
& =C_{i-\text { new }}+\bar{C}_{i} .
\end{aligned}
$$

\section{Design of bottom tee sections for tension}

Design of the bottom tee under tension based on the limit state of tensile yielding shall be performed as [4]:

$T_{u} \leq T_{c}=\phi_{t} T_{n}=\phi_{t} F_{y} A_{g}$,

where $\phi_{t}=0.9 ; A_{g}=A_{t-b o t} ; T u=T_{i}^{\max }$ is the required tensile strength calculated in previous subsection.

\section{Design of top tee Sections for compression}

If a section at a web opening is partially composite, design of compressive top tee sections based on the limit state of flexural buckling in the absence of any slender elements shall be performed as:

$P_{u} \leq P_{c}=\phi_{c} P_{n}=\phi_{c} F_{c r} A_{g}$,

where $\phi_{t}=0.9 ; A_{g}=A_{t-t o p} ; F_{c r}$ is the critical stress that shall be obtained based on the AISC provision [4].

\section{Calculation of Vierendeel moment of tee sections}

Fig. 3(c) demonstrate the dimensions and forces used to calculate the Vierendeel moments in the CBs. The required Vierendeel bending moment is calculated as follows [2]:

$M_{v r(i)}=V_{r-n e t(i)}\left(\frac{A_{t e e}}{A_{n}}\right)\left(\frac{e}{2}\right)$,

where $V_{r-\text { net }(i)}=V_{r(i)}-V_{c}$ is the net shear force; $V_{r(i)}$ is the calculated global shear at center of each opening; $V_{c}=\phi_{c v} V_{n c}=0.75 \times 12 t_{c} \sqrt{f_{c}^{\prime}}\left(h_{r}+t_{c}\right)$ is the concrete deck punching shear strength. $A_{t e e}$ is the area of the top or bottom tee section.

\section{Design of tee sections for flexure}

Design of tee sections for flexure shall be performed in accordance with the following expression [4]:

$M_{u} \leq M_{c}=\phi_{b} M_{n}=\phi_{b} F_{y} S_{x-t e e}$, 
where $\phi_{t}=0.9 ; S_{x-t e e}$ is the elastic section modulus of the tee section; $M_{u}=M_{v r(i)}^{\max }$ is the Vierendeel required flexural strength calculated according to the previous subsection. $M_{n}$ is the nominal flexural strength based on the limit states of plastic moment. The limit state of LTB shall also be checked in conformity with AISC provisions [4].

\section{Design of tee sections for combined forces}

All net sections along the length of the beam must be examined for combination of axial forces and bending moments by the resistance interaction equations [2]. If the interaction criterion of either top tee or bottom tee at each of web openings is violated, that opening shall be filled by a single plate that is the same grade and thickness as the beam web.

$I_{i}=c_{1(i)}\left(\frac{F_{\mathrm{r}(i)}}{F_{c}}\right)+c_{2(i)}\left(\frac{M_{r(i)}}{M_{c}}\right) \leq 1$,

where $F_{r(i)}$ and $F_{c}$ are the required and design axial strength; $M_{r(i)}$ and $M_{c}$ are the required and design flexural strength, at $i$ th opening respectively. The constants are either $c_{1(i)}=1$ and $c_{2(i)}=8 / 9$ when $F_{r(i)} / F_{c} \geq 0.2$ or $c_{1(i)}=0.5$ and $c_{2(i)}=1$ when $F_{r(i)} / F_{c}<0.2$.

\subsubsection{Design of tee sections and gross sections for vertical shear}

Supporting vertical shear in CBs is more critical than solid-webbed beams, since the vertical shear must pass through the perforated sections. The load that corresponds to web plate shear yielding or web plate shear buckling shall not be less than the required shear strength as [4]:

$V_{r} \leq V_{c}=\phi_{v} V_{n}=\phi_{v} 0.6 F_{y} d t_{w} C_{v}$,

where $d$ is the overall depth of the steel section which may equal $2 d_{t}$ for the net section or $d_{g}$ for the gross section; $V_{r}=V_{r}^{\max }$ is the required shear strength at the equivalent section. $\phi_{v}$ and $C_{v}$ shall be determined in conformity to AISC provisions [4].

\subsubsection{Web post lateral instability \\ Behavior}

The web post of CBs surrounded by the holes is subjected to two equal and opposite ending moments and shearing forces. In areas of high shear forces, the web post may fail by lateral instability out of the plane of the beam. Conventional design procedures for stabilizing the posts of $\mathrm{CBs}$ have considered the elastic critical load and are proved to be conservative. Aglan and Redwood [11] have introduced a rapid design aid with the buckling of the web posts, considering plasticity and strain hardening which are verified with experimental data which will be covered in the following literature. Due to symmetry, only one half of the post is taken into account.

\section{Calculation of internal forces}

Consider a unit panel segment of composite castellated beam as shown in Fig. 4(a). Required flexural strength in end portions of the web posts is to be calculated as follows [11]:

$$
M_{r h(j)}=h V_{r h(j)}=h\left|T_{L(j)}-T_{R(j)}\right|,
$$

where $h$ is the cutting depth of hexagonal opening and $j$ is the numerator of the web posts.

\section{Design procedure}

The following equation governs the design of web post for lateral instability [2].

$M_{r h} \leq M_{c h}=\phi_{b} \Psi M_{p}$,

where $M_{r h}=M_{r h(j)}^{\max }$ is the required flexural strength calculated as previous subsection. $\Psi=M_{o(c r)} / M_{p}$, is the percentage of plastics moment which is the ratio of critical end moment of the web post to its plastic bending moment for which $M_{p}=0.25 t_{w}(e+2 b)^{2} F_{y}$. Table 1 illustrates $\Psi$

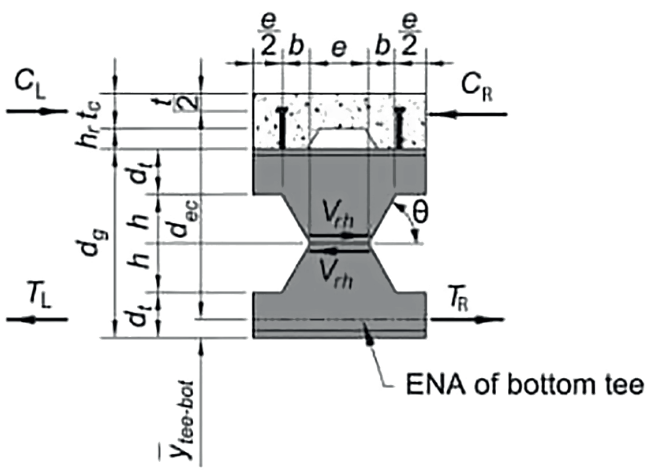

(a)

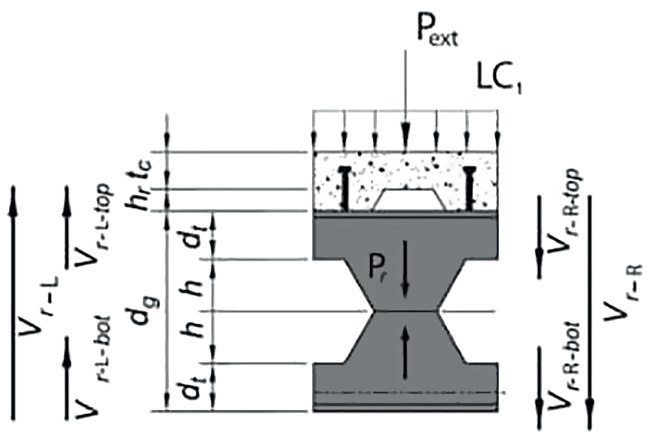

(b)

Fig 4 Terminology of (a) evaluation of web post lateral instability and (b) evaluation of web post flexural buckling for castellated beams 
equations as a function non-dimensional parameters of the web post including the ratio of hole height to minimum width of the post $(\eta=2 h / e)$ and the ratio of minimum post width to web thickness $\left(\xi=e / t_{w}\right)$.

The values of resistance factors for three specific angles of hexagonal cutting are obtained as below. For intermediate values of actual $\theta, \phi_{b}$ is determined by linear interpolation.

$$
\begin{cases}43 \leq \theta \leq 47 & \phi_{b}=0.9 \\ \theta=52.5 & \phi_{b}=0.6 \\ 58 \leq \theta \leq 72 & \phi_{b}=0.9\end{cases}
$$

\subsubsection{Design of web posts for compression}

As depicted in Fig. 4(b), the perforated web of CBs carries the vertical shear originated from direct transverse loading. When the vertical shear is equally portioned out between top and bottom chords, half of the transverse loads pass downward through the web post to the bottom chord as compressive force. Normally the magnitude of this force is not significant except for girders that are supporting the concentrated transverse shear arising from interior beams. The resultant compressive force is [10]:

$P_{r(j)}=0.5\left(V_{r-L(j)}-V_{r-R(j)}\right)$,

where $V_{L}$ and $V_{R}$ are the global vertical shear in the left and right hand side of the unit panel segment of the CBs. The design of web posts for compression shall be checked as Eq. (18) [4]:

$$
P_{r} \leq P_{c},
$$

where $P_{r}=P_{r(j)}^{\max }$ and $P_{c}$ is determined based on the limit state of flexural buckling similar to top tee section.

\subsubsection{Design of web posts for combined forces}

The proportion of the web posts that are assumed to act as a beam-column element is such that the interaction equations are satisfied. If any of the openings in the vicinity of a web post is already filled, that post would be dismissed for

Table 1 Equations of percentage of plastic moment $(\Psi)$ with respect to post non-dimensional parameters

\begin{tabular}{cccc}
\hline & \multicolumn{3}{c}{$\Psi$ Equations } \\
No. $\quad \xi$ & $\theta=45^{\circ}\left( \pm 2^{\circ}\right)$ & $\theta=60^{\circ}\left( \pm 2^{\circ}\right)$ \\
\hline 1 & 10 & $0.351-0.051 \eta+0.0026 \eta^{2} \leq 0.26$ & $0.587(0.917)^{\eta} \leq 0.493$ \\
2 & 20 & $3.276-1.208 \eta+0.154 \eta^{2}-0.0067 \eta^{3}$ & $1.96(0.699)^{\eta}$ \\
3 & 30 & $0.952-0.30 \eta+0.0319 \eta^{2}-0.0011 \eta^{3}$ & $2.55(0.574)^{\eta}$ \\
\hline
\end{tabular}

Where, $10 \leq \xi \leq 30$ and $\eta \leq 8$; interpolate between equations 1 through 3 based on actual $\xi$ for each angle of hexagonal cut. Also, interpolate for $45 \leq \theta \leq 60$ between two system of equations. interaction check. When the interaction criterion of a web post is not met, then the corresponding opening is filled.

$$
J=c_{1(j)}\left(\frac{P_{\mathrm{r}(j)}}{P_{c}}\right)+c_{2(j)}\left(\frac{M_{r h(j)}}{M_{c h}}\right) \leq 1,
$$

where $P_{r(j)}$ and $P_{c}$ are the required and design compressive strength of the web posts, $M_{r h(j)}$ and $M_{c h}$ are the required and design flexural strength of the web posts, respectively. The constants $c_{1(j)}$ and $c_{2(j)}$ are determined as before.

\subsubsection{Design of web post for horizontal shear}

The web openings in the vicinity of each web post amplify the horizontal shear crossing through the centerline of the beam. Thus horizontal shear check at the web posts is an essential criterion that shall be checked based on the limit state of shear yielding as [4]:

$V_{r h} \leq V_{c h}=\phi_{v} V_{n h}=\phi_{v} 0.6 F_{y} A_{w h}$,

where $\phi_{v}=1 ; A_{w h}=e_{t w} ; V_{r h}=V_{r h(j)}^{\max }$ is the required horizontal shear strength determined in accordance with the calculated horizontal shear force for web post buckling.

\subsubsection{Design of composite CBs for deflection Methodology}

Hexagonal perforations of CBs decrease the gross moment of inertia which is the reason for increasing the curvature at openings subjected to bending. They also cause the incompatibility of strain field and reduce the gross area for resisting shear between tees inducing Vierendeel deflections [13]. For each stage of construction pre and post concrete hardening, different approaches with utmost accuracy are adopted for estimating the maximum deflection of CBs. The deflection resulting from the dead loads and live loads should be calculated separately. The maximum deflection of girders subjected to concentrated load arising from connected interior beams is also noted.

\section{Deflection of pre composite stage}

Applying suitable stiffness reduction factor to the deflection equations of classical beam theory could imitate the reduced rigidity of web openings of $\mathrm{CBs}$ as follows [2]:

$$
\delta_{1}=\frac{5 w_{1} L^{4}}{384 \tau\left(E_{s} I_{s n}\right)},
$$

where $L$ is the total length of the beam; $I_{s n}$ is the moment of inertia of the steel net section and $\tau=0.9$ is the stiffness reduction factor; $w_{1}$ is either self-weight of the $\mathrm{CB}$ (i.e. steel beam weight together with the weight of wet concrete) or construction live load. 


\section{Deflection of post composite stage}

Benitez et al. [13] have introduced a closed form equation for evaluation of maximum deflection of composite CBs verified by comparing with experimental data which will be covered accurately in the following literature.

$\delta_{2}=\kappa \delta_{b}+\delta_{s}$,

where $\delta_{b}=\frac{5 w_{2} L^{4}}{384 E_{s} I_{c g}}$ and $\delta_{s}=\frac{w_{2} L^{2}}{8 G A_{s g}}$ are the maximum bending and shear deflection at gross section respectively; $I_{c g}$ is the transformed moment of inertia of composite gross section; $A_{s g}$ is the surface area of steel gross section; $G$ is the shear modulus of elasticity of steel; $w_{2}$ is either the dead surface load or super imposed live load.

$\kappa$ is an amplification factor which predict the increasing of bending deflection induced by embedded holes of CBs and is obtained based on the following expression.

$\kappa=1+\frac{1}{5} N_{h}(\alpha-1)\left(3 \beta^{4}-4 \beta^{3}-6 \beta^{2}+12 \beta\right)$,

where $N_{h}$ is the total number of openings; $\alpha=I_{c g} / I_{c n}$ and $\beta=(e+b) / L ; I_{c n}$ is the transformed moment of inertia of composite net section.

\section{Creep and camber}

The deflection of composite beams tends to increase with time as a result of long term creep effects. This increase is negligible except for long spans and large live loads. Roll [14] recommends using $E_{c} / 3$ in lieu of sustained concrete modulus of elasticity $\left(E_{C}\right)$ for analyzing differential shrinkage and creep effects in deflection calculations.

CBs can be cambered in order to accommodate architectural or serviceability issues. Cambering contributes to significant depth and weight saving for a floor system [15]. In this paper, cambering would be specified to control the inordinate deflections. The value of the camber would be specified as the deflection of beam self-weight.

\section{Deflection control relations}

Accuracy of the following relations ensures that the floor system does not become unfit for its intended purpose due to excessive deflection [16]:

$$
\begin{aligned}
& \delta_{L 1} \leq \delta_{a l}, \\
& \delta_{D 1}+\delta_{L 1} \leq \delta_{a t}, \\
& \delta_{L 2} \leq \delta_{a l}, \\
& \delta_{D 1}+\delta_{D 2}+\delta_{L 2} \leq \delta_{a t} .
\end{aligned}
$$

Deflection limits due to live load and total loads for floor members are $\delta_{a l}=L / 360$ and $\delta_{a t}=L / 240$, respectively.

\subsubsection{Design for vibration}

Although greater stiffness of CBs alleviates the effects of vibration of a floor system in comparison to conventional plain webbed beams, vibration remains a serious serviceability problem in flexible floor systems with long spans or light weight constituents.

\section{Calculation of first natural frequency}

Natural frequency is a fundamental characteristic for the vibration evaluation of floor systems. Multiple vibration modes with proximate frequencies is a characteristic of two-way composite floor systems. The following describes Dunkerley method used to determine the first natural frequency of simply supported beams corresponding to critical mode in resonance with a harmonic of step frequency according to treatments of AISC Design Guide 11, floor vibrations due to human activity [17].

$$
f_{n}=0.18 \sqrt{\frac{g}{\delta_{b}+\delta_{g}+\delta_{c}}},
$$

where $g=9.86\left(\mathrm{~m} / \mathrm{s}^{2}\right)$ is gravitational acceleration; $\delta_{b}$ and $\delta_{g}$ are the beam and the girder deflections due to the applied actual loads, respectively. $\delta_{c}$ is the axial shortening of the columns due to the applied actual loads, which is assumed to be negligible.

In order to represent the higher stiffness of concrete slabs under dynamic loading against static loading, it is recommended that the sustained concrete modulus of elasticity $\left(E_{c}\right)$ be taken as the $1.35 E_{c}$. Since the additional mass of the floor desensitize the oscillation, only a fraction of the superimposed live load referred as actual live load shall be considered for vibration evaluation. Reckon with the intended occupancy of the floor system, the suggested actual live load for office and residential floors are $0.5\left(\mathrm{kN} / \mathrm{m}^{2}\right)$ and $0.25\left(\mathrm{kN} / \mathrm{m}^{2}\right)$ respectively. In order to validate the use of Dunkerley equation for girders, which violate the assumption of uniform loading due to the presence of mid span concentrated mass, their calculated deflection should be multiplied by the amplification factor of $4 / \pi$.

\section{Calculation of required damping}

The following relation defines the required level of damping for restricting excessive vibration [18]:

$\zeta_{\text {req }}=35 A_{o} f_{n}+2.5$, 
where $A_{o}=A_{o t} / N_{e}$ is the initial amplitude of the floor system; $A_{o t}=D L^{3} /\left(80 E I_{c n}\right)$ is the initial amplitude of a single beam; $D$ is the maximum dynamic load factor; $N_{e}=2.97-0.0578 v+2.56 \times 10^{-8} \mu$ is the number of effective beams as a function of dimensionless factors of $v=B / d_{e}$ and $; \mu=L^{4} / I_{c n} ; d_{e}=w_{c} / \gamma_{c}$ is the effective slab thickness; $B$ is the beam spacing; $w_{c}$ is the actual slab weight and $\gamma_{c}$ is the concrete density. The force and length units of the Eq. (29) shall be kips and inches, respectively.

\section{Vibration control procedure}

A 3-step design aid is utilized to assure that the composite CBs members does not violate the vibrational limit state as follows [19]:

Step 1: The following criterion is sufficient for adequacy of vibration assessment of the floor system which could be utilized when defining some observation based parameters possible for the designer.

$\zeta_{c} \geq 10 \%$

The empirical damping $\left(\zeta_{c}\right)$ in complete floor system is a function of multiple parameters including the condition of concrete (1-3\%), type of ceiling (1-3\%), condition of mechanical systems (1-10\%) and partitions (10-20\%).

Step 2: The following criterion ensures a satisfactory vibration evaluation.

$$
f_{n} \geq 10 H z
$$

Step 3: If neither of above criteria is satisfied, the accuracy of the following equation is adequate for controlling the vibration limit state.

$$
\zeta_{\text {req }} \leq \zeta_{c}
$$

The $4 \%$ value of theoretical available damping is almost reasonable except for very quiet office environments or the operation of sensitive equipment.

\subsubsection{Composite deck-slab design}

Behavior and composite action of steel deck-slabs (i.e. DSs) are moderately complex subjects. In addition, geometrical properties of DSs differ according to their manufacturing companies. Manufacturers' catalogues are therefore generally considered to be the source of determining their dimensional and mechanical characteristics.

Although arbitrary DS profiles could be implemented, for comparison with other reference examples the DS profiles are taken from the Canam Group fabricator. Canam steel deck catalogue [20] introduces four deck profiles named P-3615, P-3606, P-3623 and P2432. Each deck profile is fabricated in three nominal thicknesses (i.e., $t_{d}$ ) of $0.79 \mathrm{~mm}, 0.91 \mathrm{~mm}$ and $1.21 \mathrm{~mm}$ steel sheets. Also six different slab thicknesses (i.e. $t_{s}$ ) are considered for each profile within values of $90,100,115,125,140,150,165,190$, and $200 \mathrm{~mm}$ in either lightweight or normal density concrete. Therefore, the catalogue introduces 144 individual DSs.

Each candidate DS is designed for its intermediate spans and is expected to act as simply supported beam with unit width. The lengths of the spans are equal to beam spacings. Each span, with respect to the condition of its neighboring spans, will be considered as either a single, double, or triple span condition.

Strength and deflection criteria of each span shall be checked as follows:

$W_{f} \leq W_{r}$,

$\Delta_{\max } \leq \Delta_{a l}$,

where $W_{f}$ is the total factored load and $W_{r}$ is the specified factored resistance; $\Delta_{\max }$ is the maximum deflection due to service live load and $\Delta_{a l}=B / 360$ is the corresponding deflection limit.

\subsection{Model formulation}

The three reasons that led us to implement a sub-optimization technique are: reducing the complexity of the problem, resolving the problem of decreasing the convergence rate due to large number of optimization variables, and analyzing the conditions around the optimum result. Thus, the entire design project was broken down into multiple subproblems that are treated independently.

To identify the number of sub-optimization problems $\left(n_{p}\right)$ pertaining to supporting steel framing, the configuration of the floor system must be considered. Based on the symmetry of the floor system, each group of interior beams, edge beams and girders was treated as an individual subprobelm. Composite DS optimization was categorized as another subproblem. The well-known three stages of formulation process for every single sub-optimization problem are described in detail in the following literature.

\subsubsection{Identification of optimization variables}

First the optimization variables of $\mathrm{CB}$ (i.e. castellated beam) subproblems are identified. Four independent variables including the depth of the web $(h)$, the web thickness $\left(t_{w}\right)$, the flange width $\left(b_{f}\right)$, and the flange thickness $\left(t_{f}\right)$ define the initial plain-web section of CBs. In order to reduce the 
complexity, these variables combined into a single steel section variable denoted by $(\mathrm{PB})$. The variables that define the dimensions of hexagonal openings of each $\mathrm{CB}$ are the height of the hole or post from the center $(h)$, minimum width of the hole or post (e), and angle of inclination of the hexagonal castellation $(\theta)$. Other variables of $\mathrm{CBs}$ are the number of filled holes $\left(N_{f h}\right)$, number of shear studs $\left(N_{s}\right)$ and the magnitude of the applied camber $\left(\delta_{c}\right)$. Thus the number of optimization variables of each $\mathrm{CB}$ shrinks to seven.

DS profiles are characterized by four independent variables. Each deck profile is defined by three variables including the depth of the ribs $\left(h_{r}\right)$, average width of the ribs $\left(w_{r}\right)$, and center-to-center distance of the ribs $\left(d_{r}\right)$ all of which are merged into a single DS profile variable denoted by (P-No.). Total slab thickness $\left(t_{s}\right)$, steel deck thickness $\left(t_{d}\right)$ and floor division number $\left(N_{f d}\right)$ are other variables for describing of DSs.

All in all, in this study 25 optimization variables are required for the statement of the design problem. The optimization variables of each subproblem and the entire optimization problem take the following form:

CB subrpoblems :

$x_{b}=\left(P B_{b}, h_{b}, e_{b}, \theta_{b}, N_{f h_{b}}, N_{s_{b}}, \delta_{c_{b}}\right) ; b=i, e, g$

DS subproblem : $x_{D S}=\left(P-N o ., t_{s}, t_{d}, N_{f d}\right)$

Composite floor system with $\mathrm{CBs}$ :

$x=\left[x_{i}, x_{e}, x_{g}, x_{D S}\right]_{1 \times 25}$

\subsubsection{Advanced cost function}

The formulation of the problem was equipped with an advanced cost function that takes into account both fabrication and material costs of all constituents of the floor system. The costs are closely related to the dimensional properties defining the good relationship between the optimization variables and the cost function. The cost function is formulated in an open manner facilitating user specific inputs based on an arbitrary production line.

The advanced cost function of each subproblem takes the following form. Individual cost contributions will be briefly described in the following literature.

$C^{i}=C_{\text {material }}^{i}+C_{\text {fabrication }}^{i} ; i=1$ to $n_{p}$

Material cost of steel CBs depends on the weight of steel elements as:

$C_{\text {material }}^{i}=\sum_{j=1}^{3} W_{j}^{i} k_{j} ; i=1$ to $n_{p}-1$, where $j=1$ to 3 corresponds to steel components of CBs including the root beams, fillers, and the shear studs, respectively; $W_{1}^{i}=(G L)_{1}^{i}$ and $W_{2,3}^{i}=\gamma_{s} V_{2,3}^{i}$ are the weight of steel components; $G^{i}$ is the weight per unit length of the root beams; $V_{2,3}^{i}$ are the volume of fillers and shear studs, respectively; $\gamma_{s}$ is the steel density; and $k_{j}$ is the cost factors of steel components.

Fabrication cost of CBs beams is directly related to the length of the manufacturing operations as follows:

$C_{\text {fabrication }}^{i}=\sum_{m=1}^{3} L_{m}^{i} k_{m} ; i=1$ to $n_{p}-1$,

where $m=1,2$ and 3 represent the individual operation of the fabrication process consisting of cutting, welding, and cambering, respectively. $L_{1}{ }^{i}$ is the cutting length; $L_{2}{ }^{i}$ is the welding length and $L_{3}{ }^{i}=I_{o}{ }^{-1}\left(I_{c n} \delta_{c}\right)^{i}$ is the normalized length of cambering; $I_{o}$ is the minimum moment of inertia of standard sections within the considered design pool; $K_{m}$ is the cost factor of each fabrication operation.

Material cost of composite DSs depends on the weight of steel elements and the volume of the concrete elements as follows:

$$
C_{\text {material }}^{i}=\sum_{j=1} W_{j}^{i} k_{j}+\sum_{r=1} V_{r}^{i} k_{r}^{\prime} ; \quad i=n_{p},
$$

where $W_{1}=A_{\text {bay }} w_{d}$ is weight of the steel plates and $V_{1}=A_{\text {bay }}\left(w_{c} / \gamma_{c}\right)$ is concrete volume; $k_{1}$ and $k_{1}{ }^{\prime}$ are the cost factors for steel decking sheets and concrete; $w_{d}$ and $w_{c}$ are the steel deck and concrete weight per unit area.

On site fabrication cost of composite DSs is related to the area of the construction operation as follows:

$$
C_{\text {fabrication }}^{i}=\sum_{m=1} A_{m}^{i} k_{m} ; \quad i=n_{p} \text {. }
$$

$A_{1}$ is surface area of the bay and $k_{1}$ is the fabrication cost factor of the DS.

It should be noted that the cost function is formulated in a way that could be rewritten based on the index notation.

\subsubsection{Constraints}

We manipulated the mathematical relations of elucidated limit states to formulate the unilateral constraints that govern the optimization problem. The constraints fall into 4 categories; the first type represents the limitations for the dimensions of the hexagonal openings and the web posts of CBs. The second and third types correspond to strength and serviceability limit states of composite CBs respectively. The constraints of the composite DS subproblem are classed as Type 4 . 
Type 1 constraints:

$$
\begin{aligned}
& h_{1}=h-(3 / 8)\left(d_{g}-2 \times t_{f}\right) \\
& h_{2}=\left(d_{g}-2 t_{f}\right)-10\left(d_{t}-t_{f}\right) \\
& h_{3}=(2 / 3) b-e \\
& h_{4}=e-2 b \\
& h_{5}=2 b+e-2 h \\
& h_{6}=\eta-8 \\
& h_{7}=10-\xi \\
& h_{8}=\xi-30 \\
& h_{9}=43-\theta \\
& h_{10}=\theta-62
\end{aligned}
$$

Type 2 constraints:

$$
\begin{aligned}
& g_{1}=\lambda_{\text {f-top tee }}-0.56 \lambda_{0} \\
& g_{2}=\lambda_{\text {s-top-tee }}-0.75 \lambda_{0} \\
& g_{3}=\lambda_{f-\text { tees }}-0.38 \lambda_{0} \\
& g_{4}=\lambda_{\text {s-tees }}-0.84 \lambda_{0} \\
& g_{5}=T_{u \text {-bottom tee }}-T_{c \text {-bottom tee }} \\
& g_{6}=P_{u \text {-top tee }}-P_{c \text {-top tee }} \\
& g_{7}=M_{u-\text { tees }}-M_{c \text {-tees }} \\
& g_{8}=N_{f h(I)}-0.5 N_{h} \\
& g_{9}=P_{u-p o s t}-P_{c-p o s t} \\
& g_{10}=M_{u-p o s t}-M_{c-p o s t} \\
& g_{11}=N_{f h(J)}-0.5 N_{h} \\
& g_{12}=V_{u-v e r-t e e s}-V_{c-\text { ver-tees }} \\
& g_{13}=V_{u-v e r-\text { gross }}-V_{c-v e r-\text { gross }} \\
& g_{14}=V_{u-h o r-p o s t}-V_{c-h o r-p o s t}
\end{aligned}
$$$$
\text { (61) } v_{i}=\sum_{n=1}^{n_{c}} \max \left[0, g_{n(i)}(x)\right] \text {, }
$$

(62) where $v_{i}$ denotes the sum of the violations of the constraints and $n_{c}$ the total number of the constraints. Here, $\varepsilon_{1}$ is set to unity and $\varepsilon_{2}$ is calculated as:

$$
\varepsilon_{2}=1.5\left(1+\frac{I N_{i}}{I N_{m}}\right),
$$

\subsubsection{Constraint handling approach}

Due to simplicity and ease of implementation, penalization approaches have been extensively developed for constraint-handling of engineering design problems. Penalization is a transformation method which solves the constraint optimization problem by transforming it into an unconstrained problem through employing a penalty function as follows [21]:

$\operatorname{eval}(x)=\sum_{i=1}^{n_{P}} n_{i} P_{i}(x) C^{i}(x)$,

where $n_{1}=N_{f d}-1 ; n_{2}=n_{3}=2 ; n_{4}=1$ and $P i\left({ }_{\mathrm{x}}\right)$ is the penalty function. We utilized the dynamic approach for defining the penalty function in our formulation as follows:

$P_{i}(x)=\left(1+\varepsilon_{1} v_{i}\right)^{\varepsilon_{2}}$,

where $I N_{i}$ is the current iteration number and $I N_{m}$ is the maximum iteration number. 


\subsection{Optimization method}

\subsubsection{Composite deck-slabs optimization}

Throughout the optimization process, all possible number of floor divisions are examined for each candidate DS. The acceptability criteria of the candidate DS with respect to the selected span length is checked and all the feasible solutions are sorted in ascending order. For optimization of supporting steel framing system, an intriguing meta-heuristic algorithm is utilized. Also in order to observe the impact of selecting higher cost decks, the entire optimization process of supporting CBs is repeated for some other decks in the vicinity of the best deck. Here, we considered the first 6 decks.

\subsubsection{Composite castellated beams optimization}

Meta-heuristics are the recent generation of optimization methods suited to optimal design of real-size structures [22]. To take advantage of these methods an established and efficient algorithm, composed of simple rule which initially mimic the free vibration of mass-spring-damper system known as Vibrating Particle System (VPS) [23] algorithm is utilized in our research. The authors rephrase the physical background of the VPS based on the free vibrations of ideal one-story frame structures which are described in detail in the following literature.

\section{Structural vibration context of VPS algorithm}

The formulation of VPS algorithm is inspired by the viscously damped free vibration of ideal one-story frame structures. We assume that the reader is familiar with the formulation of structural dynamics problems and the analysis of damped free vibration. Thus the presentation here is brief and limited to those aspects that are essential [24, 25].

Free vibration occurs when a structure vibrates subject to actions of forces inherent in the system itself and in the absence of any external excitation. Damping is an inevitable nature of real systems that makes the deformation response in free vibration decay with time, eventually returning the system back to its initial undisturbed position. A number of mechanisms such as the thermal effect of recurrent elastic straining of materials, internal friction of deformed medium, and friction at steel connections and friction between structural and non-structural elements lead to energy dissipation of the vibrating system. Damping can be mathematically idealized via a linear viscous damper i.e., dashpot.
An idealized linearly elastic one-story structure is illustrated in Fig. 5. It consists of a concentrated mass at the floor level $(m)$, axially rigid massless columns that provide lateral stiffness $(k)$ for the structure, and a dashpot with damping coefficient $c$. If the floor system is displaced laterally through some distance $u_{0}$ and led to vibrate freely, the structure will oscillate around its initial equilibrium position with a progressively decreasing amplitude. The mass of the structure is in equilibrium state under the actions of these forces, at each instant in time. This condition of dynamic equilibrium in terms of dynamic response $u(t)$ is:

$\ddot{u}(t)+2 \zeta \omega_{n} \dot{u}(t)+\omega_{n}{ }^{2} u(t)=0$

where $\zeta=c / c_{c r}$ is the damping ratio that represents the damping level of a dashpot; $c_{c r}=2 m \omega_{n}$ is the critical damping coefficient which defines the boundary of oscillatory and nonoscillatory motion and $\omega_{n}=(k / m)^{0.5}$ is the natural circular frequency.

In the motion of underdamped systems $(\zeta<1)$, damping diminishes the amplitude of deformation exponentially while the system is oscillating about its equilibrium position. In contrast, the motion of critically damped $(\zeta=1)$ or overdamped $(\zeta>1)$ systems is non-oscillatory. The solution of the equation of transient motion of under-damped system is as follows:

$u(t)=\rho e^{-\zeta \omega_{n} t} \cos \left(\omega_{D} t+\varphi\right)$.

In which $\rho=\left[u_{0}{ }^{2}+\left(\left(\dot{u}_{0}+u_{0} \zeta \omega_{n}\right) / \omega_{D}\right)^{2}\right]^{0.5}$ is the amplitude of deformation response; and $\varphi=-\tan ^{-1}\left(\left(\dot{u}_{0}+u_{0} \zeta \omega_{n}\right) / \omega_{D} u_{0}\right)$ is the phase angle. The graphical representation of viscously damped free vibration is shown in Fig. 6, in which the envelope curves $\pm \rho \exp \left(-\zeta \omega_{n} t\right)$ are approximately in contact with peak values of deformation response curve.

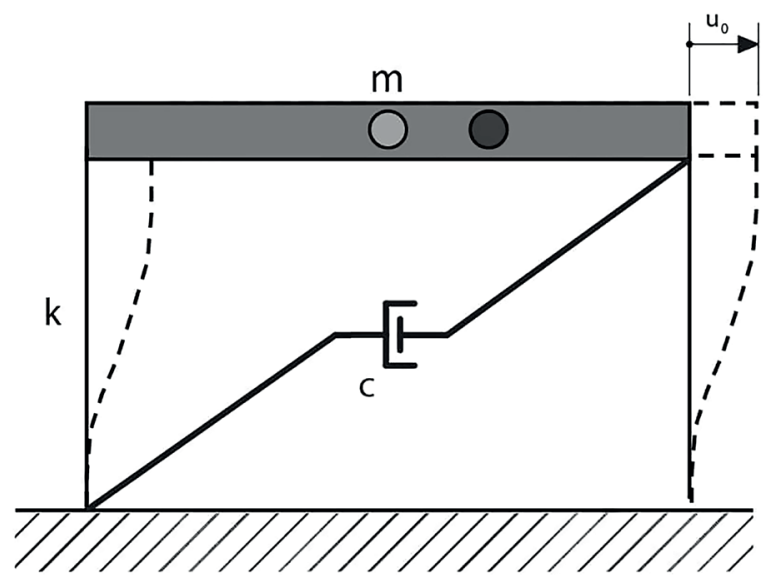

Fig. 5 Schematics of ideal one-story frame structure 


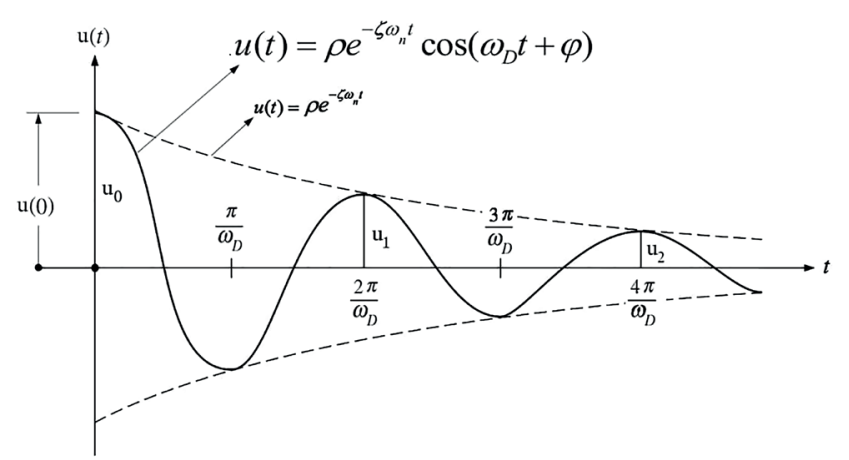

Fig 6 Response of an underdamped system subjected to an initial displacement $u_{0}$ and 0 initial velocity

The natural frequency of a damped vibration is $\omega_{D}=r_{\omega n}$, where $r=\left(1-\zeta^{2}\right)^{0.5}$ is a reduction factor which indicates that damping reduces the natural frequency of an unrealistically undamped structure. However, this reduction for most structures (e.g. buildings and bridges) is insignificant, since their damping ratios are below 0.2 .

A more important effect of damping is on the rate at which the free vibration decays or in the other words the rate of energy dissipation at deformation amplitude is dominated by damping ratio. This effect is graphically depicted in Fig. 7, for four structures with different fractions of critical damping but identical natural frequencies.

Logarithmic decrement $(\delta)$ is the natural logarithm of the ratio of two consecutive peaks of damped free vibration. Mathematical representation of the domination of damping ratio on the rate of exponential decay of free vibration is given by logarithmic decrement which for most practical structures $(\zeta<0.2)$ is defined as:

$\delta=\ln \frac{u_{i}}{u_{i+1}} \simeq 2 \pi \zeta$.

\section{Performance of the VPS algorithm}

VPS [23] is a population-based optimization algorithm that contains a number of agents instead of a single agent which enable the algorithm to explore different regions of the search space simultaneously. Each agent is modeled as a free vibrated ideal one-story frame structure with dashpot that is called particle. The performance of VPS is clearly elaborated in stages, in the following literature.

- Initialization phase

Step 1: VPS initialize the position of all particles randomly within the n-dimensional search space in order to form the Vibrating Particle matrices (VPs) as:

$$
x_{\text {initial }(j)}^{i}=x_{\min (j)}^{i}+\operatorname{rand} \cdot\left(x_{\max (j)}^{i}-x_{\min (j)}^{i}\right) \text {, }
$$

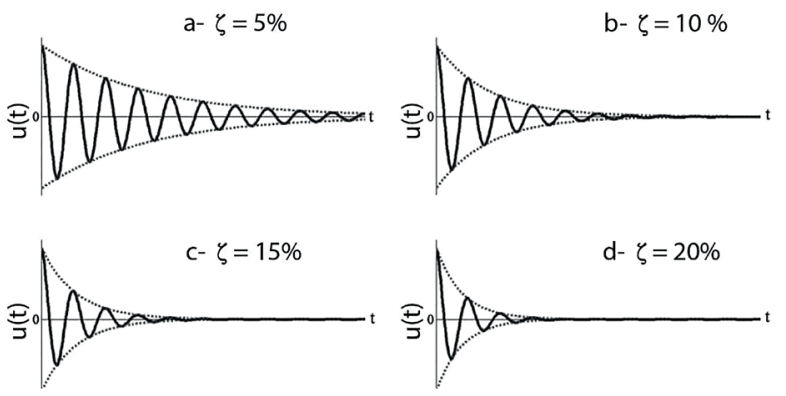

Fig 7 Free vibration of systems with four levels of damping but identical natural frequencies

where $x_{\text {initial }(j)}^{i}$ is the initial position of the $j$ th variable of the $i$ th particle; $x_{\max (j)}^{i}$ and $x_{\min (j)}^{i}$ are the side limits of the $j$ th variable and rands are random numbers drawn from the standard uniform distribution on the closed interval $[0,1]$.

Step 2: After the initial randomization of the particles, the evaluation function which is the penalized objective function of the particles is calculated to form the cost matrix (CM).

- Search Phase

Step 3: VPS utilizes a record memory to save the improvements of the population (VPM) and the corresponding cost matrix (RM) throughout the evolution. This mechanism aided by the implementation of an appropriate strategy, improves the performance of VPS without increasing computational cost. Throughout the evolution, VPS scrutinizes the variations of the calculated cost of all particles and if any improvement is detected in the CM, the upgraded value will be substituted with the previous deficient cost in the RM, followed by the substitution of its equivalent improved position in the VPM.

Step 4: Similar to free vibration of an ideal one-story frame with dashpot, VPS improves the position of the particles consecutively by oscillating them toward the equilibrium position. Individual particle of the population is regenerated by learning from three equilibrium states with different weights $\left(\omega_{i}\right)$ including: interim optimum particle $\left(P_{O}\right)$ that is the optimum solution of the population so far along with intermediate particles called superior particle $\left(P_{S}\right)$ and inferior particle $\left(P_{I}\right)$. To determine the intermediate particles at each iteration, $\mathrm{CM}$ is sorted in ascending order and PS and PI are selected randomly from the first and second halves respectively except the particle itself.

As previously stated, the rate at which the deformation response history of free vibration decays is governed by the damping ratio. VPS simulates this behavior by introducing a scalar function that is proportional to the iteration number which decrease gradually as the evolution proceeds. $c$ is a constant. 


$$
D=\left(\frac{I N_{i}}{I N_{m}}\right)^{-c}
$$

In VPS parameter $A$ is introduced to model the amplitude of free-vibration response $(\rho)$ expressed as [23]:

$A=\omega_{1}\left(P_{o}-P_{i}\right)+\omega_{2}\left(P_{S(i)}-P_{i}\right)+\omega_{3}\left(P_{I(i)}-P_{i}\right)$.

VPS regeneration formula simulates the envelope function of realistic free-vibration response i.e., $\rho \exp \left(-\zeta \omega_{n} t\right)$ by the multiplication of parameters, A and D as [23]:

$$
\begin{aligned}
& P_{n e w(i)}=\omega_{1}\left(\text { A.D.rand }+P_{o}\right)+\omega_{2}\left(\text { A.D.rand }+P_{S(i)}\right) \\
& +\omega_{3}\left(\text { A.D.rand }+P_{I(i)}\right),
\end{aligned}
$$

where $P_{i}$ and $P_{\text {new }(i)}$ respectively are the current and updated positions of the $i$ th particle.

Weight coefficients are defined to coordinate the diversification and the intensification mechanism of VPS, which weigh the interim optimum and intermediate particles relative to their importance.

$$
\sum_{k=1}^{3} \omega_{k}=1
$$

In order to hasten the rate of convergence, prior to applying the regeneration formula a stochastic model for elimination the role of $P_{I}$ shall be checked as below. Pro is a parameter within an open interval $(0,1)$.

$$
\left\{\begin{array}{l}
\text { If pro }<\text { rand } \Rightarrow w_{3}=0 \\
\text { If pro } \geq \text { rand } \Rightarrow \text { do nothing }
\end{array}\right.
$$

- Handling boundary constraints

Step 5: As stated before, VPS implements RM only for the regeneration process and utilizing this strategy may cause, the arbitrary regenerated components of a particle to violate the side constraints. In order to deal with this deleterious possibility, VPS employs a harmony searchbased handling approach, adopted form Charged System Search Algorithm (CSS) [26]. In this technique, a stochastic model specifies whether the violating component should be interchanged with a corresponding component of a random particle in RM or should it be determined randomly in a search space.

$\{$ If $H M C R<$ rand $\Rightarrow$ choose a random value from $\mathbb{S}$

If $H M C R \geq$ rand $\Rightarrow$ choose a random value from RM

where $H M C R$ is the harmony memory considering rate variable between 0 and 1 .

\section{- Termination}

Step 6: The optimization process from step 2 to 4 is performed successively and the population of solutions improves progressively throughout the evolution. After the preset maximum number of iterations, the optimization process is terminated and the particle with the lowest price becomes the final solution of the problem, and can be readily extracted from the VPM.

\section{Results and discussion}

\subsection{General statements}

Three distinct design examples are studied to evaluate the validity of the proposed optimization program. As shown in Fig. 8, the optimum design of a single bay is considered in the examples and this can be repeated in different directions to cover a complete floor plan. In order to simulate the effect of adjacent bays and exterior walls the additional uniform dead and live loads may be applied to exterior beams.

MATLAB software is used for both modeling the optimization process and performing the structural design. Cost coefficients are given in Table 2 [7, 9]. In order to allow for long term creep and shrinkage effects in the deflection calculation, one must set the creep coefficient $\delta_{\text {per }}$ equal to 1 and for ignoring its effect it must be taken as 0 . The value of $\delta_{\text {per }}$ is set to 1 for all of the examples. All connections are supposed to be simple connections and the span of both interior beams and edge beams are assumed to be identical.

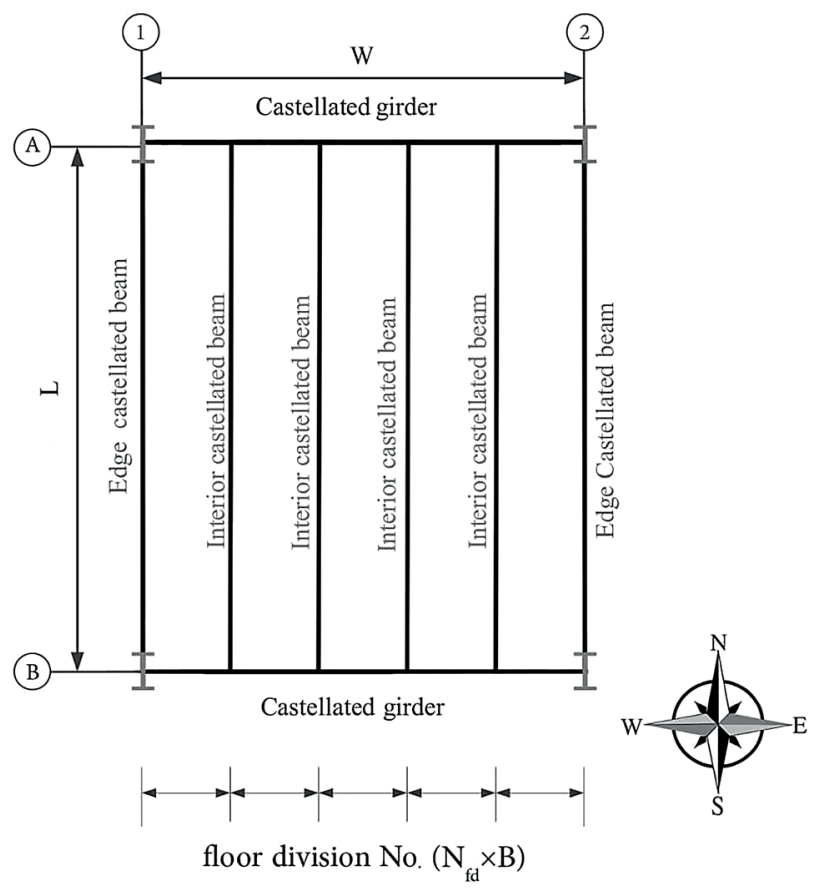

Fig. 8 Structural framing layout of the floor systems to be optimized 
Table 2 Cost factors of various floor components

\begin{tabular}{lcc}
\hline Floor components & Cost factors $(\$)$ & Units \\
\hline Steel beams & 2.86 & per kg \\
Steel deck & 2.25 & per kg \\
Shear studs & 2.4 & per kg \\
Concrete & 131 & per $\mathrm{m}^{3}$ \\
Welding & 1 & per m \\
Cutting & 0.8 & per m \\
Cambering & 1.25 & per $\mathrm{mm}$ \\
Construction $(\mathrm{DS})$ & 10.8 & per $\mathrm{m}^{2}$ \\
\hline
\end{tabular}

The result of sensitivity analysis on population size, $c$, $\omega_{1}, \omega_{2}$ and pro reveals that values $20,0.05,0.3,0.3$ and 0.7 give rise to the most suitable performance of the VPS [27]. The value of HMCR is set to 0.95 [26]. Regarding the steel decks, either one or both of P-2432 and P-3623 Canam deck profile with normal weight concrete is utilized for the examples. The triple span condition is assumed for all spans and the shoring spans are not considered. Also, a value of $4.2 \%$ of theoretical available damping is used for all the examples.

\subsection{Example 1}

\subsubsection{Problem statement}

In order to validate the performance of the proposed optimization program, we optimized a $50 \mathrm{ft} \times 32 \mathrm{ft}$ rectangular floor system adopted from the AISC Design Guide 31 [2]. Although no optimization technique is utilized in the reference example, due to similarity of the utilized design theories of composite $\mathrm{CBs}$, it is recognized as the most appropriate benchmark example. The steel beams are supposed to be fabricated by ASTM A992 steel type and are sized from a set of $233 \mathrm{~W}$-shapes sections given in ASTM A6 chosen based on area and inertia properties [28]. For consistency with the benchmark example, only the 5-inch slab thicknesses of P-3623 Canam deck profile are utilized. The corresponding input design parameters are summarized in Table 3.

\subsubsection{Presentation and assessment of the results}

Performance validity of our proposed program is evidenced by the results presented in Table 4. Overall, it is clear that our solution compared to a classical design method, with the intention to utilize cross sections as fully as possible, has reduced the cost of the whole floor system by about $15 \%$. The convergence history for the optimal solution is plotted in Fig. 9.

In composite construction of castellated beams, the top tee works in conjunction with concrete slab, thus the top tee is not usually subjected to considerable amounts of axial force. Interestingly, while the AISC Design Guide 31 [2] utilized a classical design approach, the optimum cost of interior beams in our solution yields only a $2 \%$ reduction. This is because the benchmark example specifies asymmetric sections for interior beams, using a smaller root beam for the top tee.

For the purpose of a fair analogy, if we assume that the design guide also uses symmetrical sections, the price of interior beams increases from $\$ 10050$ to $\$ 12500$. Our solution for interior beams therefore greatly boosts cost-reduction from $2 \%$ to $21 \%$.

Table 3 Input design parameters for the $50 \mathrm{ft} \times 32 \mathrm{ft}$ floor system

\begin{tabular}{|c|c|c|c|c|c|}
\hline Bay Size (ft) & Material properties (ksi) & Material Density (pcf) & Deal Loads (psf) & Live Loads (psf) & Misc. \\
\hline$L=50$ & $E=29000$ & $\gamma_{s}=491$ & $W_{d s}=20$ & $W_{l}=100$ & $d_{s}=0.75$ \\
\hline$W=32$ & $F_{y}=50$ & $\gamma_{c}=145$ & $+W_{c}$ & $W_{l c}=0$ & $\delta_{a l}=\mathrm{L} / 360$ \\
\hline- & $F_{u}=65$ & - & $+W_{s d}$ & $W_{l a}=11$ & $\delta_{a t}=\mathrm{L} / 240$ \\
\hline - & $F_{u s}=65$ & - & $+W_{b}$ & - & $\delta_{p e r}=1$ \\
\hline- & $f_{c}=3$ & - & - & - & $\zeta_{c}=4.2 \%$ \\
\hline
\end{tabular}

$E=$ modulus of elasticity of steel; $F_{y}=$ minimum yield stress $; F_{u}=$ minimum tensile strength; $f_{c}=$ compressive strength of concrete; $W_{d s}=$ dead surface load; $W_{d c}=$ dead weight of the concrete; $W_{d d}=$ dead weight of the steel deck; $W_{d b}=$ dead weight of the steel beam; $W_{l}=$ minimum live load; $W_{l c}=$ construction live load; $W_{l a}=$ actual live load

Table 4 Comparison of cost distribution for the $50 \mathrm{ft} \times 32 \mathrm{ft}$ floor system with literature data

\begin{tabular}{|c|c|c|c|c|c|c|c|c|c|}
\hline \multirow{2}{*}{ Publication } & \multirow{2}{*}{$\begin{array}{l}\text { Design } \\
\text { method }\end{array}$} & \multirow{2}{*}{$\begin{array}{c}\text { Num. of } \\
\text { Limit states }\end{array}$} & \multirow{2}{*}{$\begin{array}{l}\text { Floor height } \\
\text { (in) }\end{array}$} & \multicolumn{3}{|c|}{ Cost of steel beams (\$) } & \multicolumn{3}{|c|}{ Cost distribution (\$) } \\
\hline & & & & Interior beams & Edge beams & Girders & Steel beams & Deck Slab & floor system \\
\hline Design guide [2] & $\begin{array}{c}\text { Classical } \\
\text { design }\end{array}$ & 18 & 35.8 & 10050 & 6700 & 6550 & 23300 & 8100 & 31400 \\
\hline Present Work & $\begin{array}{c}\text { Optimum } \\
\text { design }\end{array}$ & 21 & 28.7 & 9845 & 4605 & 5200 & 19650 & 6975 & 26625 \\
\hline
\end{tabular}




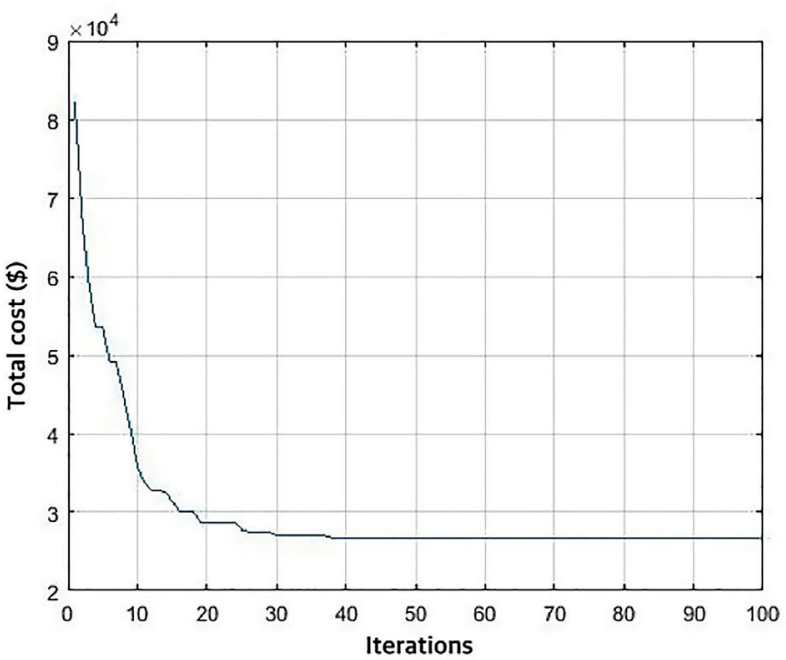

Fig. 9 The cost history graph for the $50 \mathrm{ft} \times 32 \mathrm{ft}$ floor system

By altering the point of observation, the benchmark example assigned similar sections to both groups of interior beams and edge beams, but our program treats edge beams as an individual subproblem. Table 5 shows that, compared to interior beams, $15(\mathrm{Ib} / \mathrm{ft})$ lighter sections are chosen for the edge beams and $\$ 1960$ is saved which leads to an almost $31 \%$ cost reduction compared to that in the design guide (Table 4).

As it has emerged from our optimum solution, the structural depth of the floor system is 7.1 inches and almost $20 \%$ more shallow than that in the AISC Design Guide. This reveals the fact that our program is able to reduce the floor to floor height of each story level, leading to a more economical construction method.
In terms of basic variables, optimal design demonstrated a significant reduction of horizontal cutting length by about $31 \%$, while in turn a moderate average variation of about $13 \%$ and $18 \%$ is observed in cutting angle and cutting height of interior beams, respectively (Table 5).

\subsection{Example 2}

\subsubsection{Problem statement}

For the purpose of comparison, an interior $10 \mathrm{~m} \times 8 \mathrm{~m}$ floor configuration optimally designed by Poitras et al. [7] is solved by our proposed optimization program. The structural beams are supposed to be fabricated by EU S355 steel type and are sized using a set of 125 economical W-Shapes found in the Canadian Institute of Steel Construction (CISC) Handbook [29]. Both P-2432 and P-3623 composite deck profiles of Canam catalogue are utilized for this example. The pertinent input design parameters are shown in Table 6 .

\subsubsection{Presentation and assessment of the results}

In order to conduct an impartial comparison, the cost factor for shear stud is equated with that used in the benchmark example. The optimum solution reached by Poitras et al. [7] for the floor layout using conventional plain-webbed beams and our optimum solution using high stiffness castellated beams are both illustrated in Table 7 .

The difference between the final cost of our study compared to the first study does not exceed $0.6 \%$. Plus the fact that, our solution reduced the structural depth of the floor by $16.8 \%$.

Table 5 Comparison of basic variables of castellated beams for the $50 \mathrm{ft} \times 32 \mathrm{ft}$ floor system

\begin{tabular}{|c|c|c|c|c|c|c|c|c|c|}
\hline \multirow{3}{*}{$\begin{array}{l}\text { Basic } \\
\text { variables }\end{array}$} & \multicolumn{3}{|c|}{ Interior beams } & \multicolumn{3}{|c|}{ Edge beams } & \multicolumn{3}{|c|}{ Girders } \\
\hline & \multicolumn{2}{|c|}{ AISC design guide 31 [2] } & \multirow{2}{*}{$\begin{array}{c}\text { Present } \\
\text { work }\end{array}$} & \multicolumn{2}{|c|}{ AISC design guide 31 [2] } & \multirow{2}{*}{$\begin{array}{c}\text { Present } \\
\text { work }\end{array}$} & \multicolumn{2}{|c|}{ AISC design guide 31 [2] } & \multirow{2}{*}{$\begin{array}{c}\text { Present } \\
\text { work }\end{array}$} \\
\hline & Top & Bottom & & Top & Bottom & & Left & Right & \\
\hline$P B$ & $\mathrm{~W} 21 \times 44$ & $\mathrm{~W} 21 \times 57$ & $\mathrm{~W} 21 \times 50$ & $\mathrm{~W} 21 \times 44$ & $\mathrm{~W} 21 \times 57$ & $\mathrm{~W} 18 \times 35$ & $\mathrm{~W} 24 \times 55$ & $\mathrm{~W} 27 \times 102$ & $\mathrm{~W} 24 \times 62$ \\
\hline$h$ (in) & 9.7 & 10.1 & 11.7 & 9.7 & 10.1 & 9.6 & \multicolumn{2}{|c|}{ N/A } & 7.6 \\
\hline$\theta^{\circ}$ & 60.41 & 61.4 & 53.1 & 60.41 & 61.4 & 53.3 & & & 56.4 \\
\hline$e($ in) & \multicolumn{2}{|c|}{8} & 5.9 & \multicolumn{2}{|c|}{8} & 4.9 & \multicolumn{2}{|c|}{ N/A } & 5 \\
\hline$N_{s s}$ & \multicolumn{2}{|c|}{54} & 48 & \multicolumn{2}{|c|}{54} & 34 & \multicolumn{2}{|c|}{18} & 34 \\
\hline$N_{b}$ & \multicolumn{2}{|c|}{3} & 3 & \multicolumn{2}{|c|}{2} & 2 & \multicolumn{2}{|c|}{2} & 2 \\
\hline
\end{tabular}

Table 6 Input design parameters for the $10 \mathrm{~m} \times 8 \mathrm{~m}$ steel floor

\begin{tabular}{|c|c|c|c|c|c|c|}
\hline Bay Size (m) & Material properties (MPa) & Material density $\left(\mathrm{kg} / \mathrm{m}^{3}\right)$ & Deal Loads (kPa) & Live Loads $(\mathrm{kPa})$ & Add. Loads $(\mathrm{kN} / \mathrm{m})$ & Misc. \\
\hline$L=10$ & $E=205000$ & $\gamma_{s}=7850$ & $W_{d s}=1.6$ & $W_{l}=4.8$ & $w_{d g}=10$ & $d_{s}=19$ \\
\hline$W=8$ & $F_{y}=3550$ & $\gamma_{c}=2400$ & $+W_{c}$ & $W_{l c}=0$ & $w_{l g}=14$ & $\delta_{a l}=\mathrm{L} / 360$ \\
\hline - & $F_{u}=470$ & - & $+W_{s d}$ & $W_{l a}=0.5$ & $w_{d e}=4$ & $\delta_{a t}=\mathrm{L} / 240$ \\
\hline- & $F_{u s}=450$ & - & $+W_{b}$ & - & $w_{l e}=4$ & $\delta_{p e r}=1$ \\
\hline- & $f_{c}=20$ & - & - & - & - & $\zeta_{c}=4.2 \%$ \\
\hline
\end{tabular}


If we compare the deck variables of the present study with the benchmark example, we find out that a $0.15 \mathrm{~mm}$ increase in steel deck thickness for a constant concrete depth (Table 8) produces a $9.3 \%$ increase in the deck cost (Table 7 ). On the other hand, a $15 \mathrm{~mm}$ reduction in concrete thickness with the deck thickness unchanged, yields only a $4 \%$ cost reduction (Table 9). This analogy highlights the fact that the total cost of the floor system is more sensitive to variation of steel deck thickness as compared to concrete depth.

The optimum costs obtained by Poitras et al. [7] for the present floor configuration with respect to predefined $50 \%$, $60 \%$ and $75 \%$ partial composite actions are $\$ 15360, \$ 15225$ and $\$ 15210$ respectively. Curiously they also eliminate the composite action by removing the stud anchors. The cost of this non-composite floor system dropped to $\$ 14832$.

According to Salmon et al. [30] elimination of the composite action between concrete slab and steel beams contributes to discontinuity in strain distribution at the plane of contact and nullifies the interaction of the two materials. Nullifying the interaction of two materials contradicts the objective of structural composite systems whose mechanical performances are designed to be superior than to those monolithic materials acting independently. Therefore, this anomaly is discarded in the performance comparison.

They also state that if a full interaction exists in a structural composite beam, the corresponding strain distribution will retain single natural axis and no discontinuity

Table 7 Comparison of cost distribution for the $10 \mathrm{~m} \times 8 \mathrm{~m}$ floor system with literature data

\begin{tabular}{|c|c|c|c|c|c|c|}
\hline Researchs & Design methods & Number ofconstraints & Floor height (mm) & Deck cost $(\$)$ & Beam cost $(\$)$ & Total cost (\$) \\
\hline Poitras et al. [7] & PSO, LSD - CSA 16 & 4 & 668 & 3615 & 11595 & 15210 \\
\hline Peresent Study & VPS, LSD - AISC 16 & 31 & 555 & 3950 & 11350 & 15300 \\
\hline
\end{tabular}

Table 8 Comparison of basic variables of $10 \mathrm{~m} \times 8 \mathrm{~m}$ floor system with the literature data

\begin{tabular}{|c|c|c|c|c|c|c|c|c|c|}
\hline Researches & Root sections & Composite status & $h(\mathrm{~mm})$ & $e(\mathrm{~mm})$ & $\theta^{\circ}$ & $N_{f d}$ & Deck profile & $t_{d}(\mathrm{~mm})$ & $t_{s}(\mathrm{~mm})$ \\
\hline \multirow{3}{*}{ Poitras et al. [7] } & $\mathrm{W} 460 \times 60$ & Partial & & & & & & & \\
\hline & $\mathrm{W} 460 \times 60$ & Partial & $\mathrm{N} / \mathrm{A}^{\mathrm{a}}$ & N/A & N/A & 3 & P-2432 & 0.76 & 140 \\
\hline & W5 $530 \times 82$ & Partial & & & & & & & \\
\hline \multirow{3}{*}{ Peresent Study } & $W 310 \times 60$ & Full & 160 & 95 & 55.4 & & & & \\
\hline & $\mathrm{W} 250 \times 45$ & Full & 143 & 82 & 54.6 & 3 & P-2432 & 0.91 & 140 \\
\hline & $\mathrm{W} 410 \times 100$ & Partial & 163 & 118 & 58 & & & & \\
\hline
\end{tabular}

${ }^{a}$ Not applicable

Table 9 Basic variables and cost distribution of our first six solutions for the $10 \mathrm{~m} \times 8 \mathrm{~m}$ floor system

\begin{tabular}{|c|c|c|c|c|c|c|c|c|c|c|c|c|}
\hline \multicolumn{6}{|c|}{ Basic variables of $\mathrm{CB}$} & \multicolumn{4}{|c|}{ Basic variables of DS } & \multicolumn{3}{|c|}{ Cost distribution $(\$)$ [order] } \\
\hline $\begin{array}{l}\text { Initial } \\
\text { sections }\end{array}$ & $\begin{array}{c}h \\
(\mathrm{~mm})\end{array}$ & $\begin{array}{c}e \\
(\mathrm{~mm})\end{array}$ & $\theta^{\circ}$ & $N_{f h}$ & $\begin{array}{c}\text { Camber } \\
(\mathrm{mm})\end{array}$ & $\begin{array}{c}\text { Deck } \\
\text { profile }\end{array}$ & $\begin{array}{c}t_{d} \\
(\mathrm{~mm})\end{array}$ & $\begin{array}{c}t_{s} \\
(\mathrm{~mm})\end{array}$ & $N_{f d}$ & $\begin{array}{l}\text { deck } \\
\text { slab }\end{array}$ & $\begin{array}{c}\text { Steel } \\
\text { beams }\end{array}$ & $\begin{array}{c}\text { floor } \\
\text { system }\end{array}$ \\
\hline $\begin{array}{l}W 310 \times 60 \\
W 250 \times 50 \\
W 410 \times 100\end{array}$ & $\begin{array}{l}160 \\
143 \\
163\end{array}$ & $\begin{array}{c}95 \\
82 \\
118\end{array}$ & $\begin{array}{c}55.5 \\
54.6 \\
58\end{array}$ & 1 & 0 & P-2432 & 0.091 & 140 & 3 & $\begin{array}{c}3950 \\
{[6]}\end{array}$ & $\begin{array}{c}11350 \\
{[1]}\end{array}$ & $\begin{array}{c}15300 \\
{[1]}\end{array}$ \\
\hline $\begin{array}{l}W 310 \times 60 \\
W 310 \times 60 \\
W 410 \times 100\end{array}$ & $\begin{array}{l}157 \\
164 \\
170\end{array}$ & $\begin{array}{c}95 \\
88 \\
125\end{array}$ & $\begin{array}{c}55.3 \\
54 \\
57.7\end{array}$ & 0 & 0 & P-2432 & 0.091 & 125 & 3 & $\begin{array}{c}3790 \\
{[5]}\end{array}$ & $\begin{array}{c}11945 \\
{[2]}\end{array}$ & $\begin{array}{c}15735 \\
{[2]}\end{array}$ \\
\hline $\begin{array}{l}W 310 \times 60 \\
W 310 \times 60 \\
W 410 \times 100\end{array}$ & $\begin{array}{l}160 \\
150 \\
143\end{array}$ & $\begin{array}{c}99 \\
83 \\
106\end{array}$ & $\begin{array}{c}55.5 \\
54.2 \\
58\end{array}$ & 0 & 0 & P-3623 & 0.091 & 125 & 3 & $\begin{array}{c}3715 \\
{[3]}\end{array}$ & $\begin{array}{c}12020 \\
{[3]}\end{array}$ & $\begin{array}{c}15735 \\
{[3]}\end{array}$ \\
\hline $\begin{array}{l}W 250 \times 39 \\
W 250 \times 45 \\
W 460 \times 113\end{array}$ & $\begin{array}{l}134 \\
143 \\
203\end{array}$ & $\begin{array}{c}80 \\
76 \\
133\end{array}$ & $\begin{array}{l}55.1 \\
53.8 \\
56.2\end{array}$ & 0 & 26 & P-3623 & 0.076 & 125 & 4 & $\begin{array}{c}3435 \\
{[1]}\end{array}$ & $\begin{array}{c}12490 \\
{[6]}\end{array}$ & $\begin{array}{c}15925 \\
{[4]}\end{array}$ \\
\hline $\begin{array}{l}W 250 \times 33 \\
W 250 \times 39 \\
W 410 \times 100\end{array}$ & $\begin{array}{l}142 \\
130 \\
167\end{array}$ & $\begin{array}{c}78 \\
69 \\
141\end{array}$ & $\begin{array}{c}54.2 \\
54.2 \\
60\end{array}$ & 1 & 25 & P-3623 & 0.091 & 125 & 5 & $\begin{array}{c}3720 \\
{[4]}\end{array}$ & $\begin{array}{c}12270 \\
{[4]}\end{array}$ & $\begin{array}{c}15990 \\
{[5]}\end{array}$ \\
\hline $\begin{array}{l}W 250 \times 33 \\
W 250 \times 39 \\
W 410 \times 100\end{array}$ & $\begin{array}{l}139 \\
143 \\
153\end{array}$ & $\begin{array}{c}77 \\
75 \\
124\end{array}$ & $\begin{array}{l}54 \\
54 \\
59\end{array}$ & 0 & 0 & P-3623 & 0.076 & 150 & 5 & $\begin{array}{c}3700 \\
{[2]}\end{array}$ & $\begin{array}{c}12330 \\
{[5]}\end{array}$ & $\begin{array}{c}16030 \\
{[6]}\end{array}$ \\
\hline
\end{tabular}


would be observed at the plane of contact. Also the chord forces in full composite action are larger than those in partial action [30]. Hence it is recognized as a structurally more efficient status of composite action. However, it does not always give rise to the most economical solution as it is clear from the results of the $1^{\text {st }}$ study.

In the study of Poitras et al. [7], the desired percentage of composite action within the specified range must be entered as input data for the optimization program. On the contrary, in our study, if a candidate steel-concrete beam violates the assumption of full composite action the program is able to design that section as partially composite to save costs. At this point the radical difference between our program and that in the work done by Poitras et al. [7] becomes more comprehensible, in that the cost of $\$ 15210$ is obtained by the assumption of predefined $75 \%$ composite action for all groups of beams which deviates from our treatment regarding the composite action.

The first six solutions of the present study for the $8 \mathrm{~m} \times 10 \mathrm{~m}$ floor layout based on the cost of the complete floor system is illustrated in Table 9 in ascending order. Also the order of the cost of the floor constituents namely the deck-slab and the steel framing is shown in brackets. It can be deduced from the table that the order of the final price does not necessarily follow the order of the deckslab cost. The results of the best floor which possess the worst deck is clear evidence for this fact. Hence one can conclude that obtaining the minimum cost of the composite floor system without considering the higher cost decks other than the best deck is not attainable.

We can also change our perspective and highlight the fact that the same statement is valid for the supporting steel framing. Basically, the order of the total cost of the floor system is not essentially identical to that of the steel beams. This statement emphasizes that a simultaneous optimization considering the reciprocal effects of the constituents of the steel-concrete floor systems is an inevitable procedure for obtaining the most economical design solution.

An individual deck profile has its own specified range of span (i.e. distance of the beams). Thus utilizing a variety of deck profiles in contrast to single deck utilization, enables the optimization program to examine higher numbers of floor divisions (i.e. $N_{f d}$ ). This statement can be intelligibly deduced from Table 9 in which the floors with the P-3623 deck profile possess 4, 5 and even 6 interior beams as compared to the floors with P-2432 deck profile which only have 4 interior beams.

The variables of the $4^{\text {th }}$ and the $5^{\text {th }}$ floor systems reveal that the program could effectively save costs by reducing excessive deflection by specifying $26 \mathrm{~mm}$ and $25 \mathrm{~mm}$ camber respectively. Furthermore, the optimum dimensions of hexagonal openings for all types of beams effectually identified.

As in the case of $2^{\text {nd }}$ and $3^{\text {rd }}$ floor systems with proximate final prices, each of the floor systems can be arbitrarily selected for a specific construction project after due consideration of different factors like structural depth, number of floor divisions, constructional concerns or availability of materials.

Table 10 shows both filling pattern and composite status of the web openings of castellated beams considering vertical symmetry. It is noteworthy that utilizing W410 $\times 100$ as root section of girders necessitates partial interaction of composite sections at all web openings as opposed to edge and interior beams which manifest complete steel-concrete interaction. The same results could be presented for other beams omitted for brevity.

This example is also solved by ASTM A6 W-sections and European standard beams. The optimum cost of the floor for each set of sections dropped significantly to $\$ 11950$ and $\$ 12885$ showing a $20 \%$ and an almost $14 \%$ reduction respectively compared to Canadian sections.

\subsection{Example 3}

\subsubsection{Problem statement}

The optimal design of $6 \mathrm{~m} \times 7 \mathrm{~m}$ floor layout is examined as the last example. The structural beams are fabricated by DIN 17100 St 37.2 and St 52.3 steel types and are sized within the complete set of 217 European standard wide flange $\mathrm{H}$ beams and universal I beams chosen based on area and inertia properties. P-2432 and P-3623 of Canam composite steel decks are utilized for this example.

Table 10 Filling pattern and composite status of girders for the $10 \mathrm{~m} \times 8 \mathrm{~m}$ floor system

\begin{tabular}{cccccccccccccc}
\hline & $x_{i}(\mathrm{~cm})$ & 0 & 28 & 72 & 116 & 160 & 204 & 248 & 291 & 335 & 379 & $\mathrm{CL}$ \\
Girders & Filling pattern & End & 0 & 0 & 0 & 0 & 0 & 0 & 0 & 0 & 0 & 0 & $\mathrm{P}$ \\
& Composite status & $\mathrm{NA}$ & $\mathrm{P}$ & $\mathrm{P}$ & $\mathrm{P}$ & $\mathrm{P}$ & $\mathrm{P}$ & $\mathrm{P}$ & $\mathrm{P}$ & $\mathrm{P}$ & $\mathrm{P}$ & $\mathrm{P}$ \\
\hline
\end{tabular}

$0=$ opening is not filled; $1=$ opening is infilled; $F=$ full composite action; $P=$ partial composite action 
This example is solved twice. First the input is adjusted to be identical to that in the work done by Kaveh and Ghaffari [9]. In conformity with their work St 37.2 steel type and I sections from IPE140 to IPE600 are utilized as the design pool for steel sections. They also utilized the P-2432 Canam deck profile. In order to simulate the effect of wall loads and neighboring bays, twice the typical loads of the existing bay are applied to the side beams. The design parameters for the first solution are listed in Table 11.

\subsubsection{Description of the results}

Tables 12 and 13 compare the cost distribution and basic variables pertaining to the optimum solutions of the two researches respectively. Disregarding the construction cost which is invariable, the rate of change of the composite deck-slab cost is more sensitive to an increment of deck thickness rather than incremental changes of concrete thickness. Hence a $0.015 \mathrm{~cm}$ reduction in deck thickness resulted in an $8.5 \%$ drop in deck-slab cost. At the same time, a $15 \%$ improvement could be observed in our solution pertaining to the castellated beams as compared to that of the 1st study. Overall a significant reduction of $17.2 \%$ was observed in the final price of complete floor system as compared to the solution of Kaveh and Ghaffari [9]. Our program also decreased the structural depth of the floor system by $14 \mathrm{~cm}$ - equivalent to $22.4 \%$.

\subsubsection{Discussing the results}

The AISC specification [4] for determination of design positive flexural strength of composite beams with stud anchors, have introduced two methods including plastic stress distribution for compact webs and elastic stress distribution for either noncompact or slender webs. Kaveh and Ghafari [9] utilized the latter approach in which the elastic properties and effect of shoring shall be taken into account. In this method the maximum global moment is verified to be smaller than the ultimate moment capacity determined by elastic flexural formulas such that the compressive stress is $0.7 f_{c}^{\prime}$ in the top fiber of the transformed net section and $F_{y}$ in the bottom fiber. On the other hand, we assume that the beam at the net sections is fully composite such that all of the compression forces resulting from global moments are resisted by the concrete sections and that the bottom tees resist all tension forces. The resultant axial forces are calculated by dividing the global moments by the distance between the centroids of the concrete flanges and the bottom tees assuming a Whitney rectangular stress distribution in the topping concretes and uniform tensile stress distribution in the bottom tees. Validity of this assumption is to be verified in the design process.

In the treatment of Kaveh and Ghaffari [9] regarding Vierendeel bending the summation of elastic stresses resulting from global moments at the bottom fiber of the

Table 11 Input design parameters for the $6 \mathrm{~m} \times 7 \mathrm{~m}$ floor system for the first solution

\begin{tabular}{|c|c|c|c|c|c|c|}
\hline Bay Sizes (m) & $\begin{array}{l}\text { Material properties } \\
\qquad\left(\mathrm{kg} / \mathrm{cm}^{2}\right)\end{array}$ & $\begin{array}{l}\text { Material densities } \\
\qquad\left(\mathrm{kg} / \mathrm{cm}^{3}\right)\end{array}$ & Deal Loads $\left(\mathrm{kg} / \mathrm{m}^{2}\right)$ & Live Loads $\left(\mathrm{kg} / \mathrm{m}^{2}\right)$ & Add. Loads $(\mathrm{kg} / \mathrm{m})$ & Misc. \\
\hline$L=6$ & $E=2039000$ & $\gamma_{s}=7850$ & $W_{d s}=163$ & $W_{l}=490$ & $w_{d g}=326$ & $\delta_{a l}=\mathrm{L} / 360$ \\
\hline$W=7$ & $F_{y}=2350$ & $\gamma_{c}=2400$ & $+W_{c}$ & $W_{l a}=51$ & $w_{l g}=980$ & $\delta_{a t}=\mathrm{L} / 240$ \\
\hline- & $F_{u}=3400$ & - & $+W_{s d}$ & $W_{l c}=0$ & $w_{d e}=326$ & $\delta_{p e r}=1$ \\
\hline- & $F_{u s}=4500$ & - & $+W_{b}$ & - & $w_{l e}=980$ & $\zeta_{c}=4.2 \%$ \\
\hline- & $f_{c}=250$ & - & - & - & - & $d_{s}=19$ \\
\hline
\end{tabular}

Table 12 Comparison of cost distribution for the $6 \mathrm{~m} \times 7 \mathrm{~m}$ floor system

\begin{tabular}{|c|c|c|c|c|c|c|}
\hline Researches & Design methods & No. of constraints & Floor Heights $(\mathrm{cm})$ & Deck costs $(\$)$ & Beams costs $(\$)$ & Total costs $(\$)$ \\
\hline Kaveh \& Ghafari [9] & ECBO [22], LRFD - AISC 10 & 14 & 62.5 & 1980 & 5535 & 7515 \\
\hline Peresent study & VPS, LRFD - AISC-16 & 31 & 48.5 & 1825 & 4700 & 6525 \\
\hline
\end{tabular}

Table 13 Comparison of the basic variables for the $6 \mathrm{~m} \times 7 \mathrm{~m}$ floor system

\begin{tabular}{|c|c|c|c|c|c|c|c|c|c|c|c|}
\hline \multirow{6}{*}{ 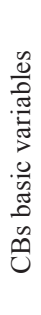 } & & \multicolumn{2}{|c|}{ Interior beams } & \multicolumn{2}{|c|}{ Edge beams } & \multicolumn{2}{|c|}{ Girders } & \multirow{3}{*}{ 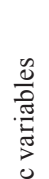 } & & \multicolumn{2}{|c|}{ Deck-slabs } \\
\hline & & $\begin{array}{c}\text { Kaveh \& } \\
\text { Ghafari [9] }\end{array}$ & $\begin{array}{l}\text { Present } \\
\text { study }\end{array}$ & $\begin{array}{c}\text { Kaveh \& } \\
\text { Ghafari [9] }\end{array}$ & $\begin{array}{l}\text { Present } \\
\text { study }\end{array}$ & $\begin{array}{c}\text { Kaveh \& } \\
\text { Ghafari [9] }\end{array}$ & $\begin{array}{l}\text { Present } \\
\text { study }\end{array}$ & & & $\begin{array}{c}\text { Kaveh \& } \\
\text { Ghafari [9] }\end{array}$ & $\begin{array}{c}\text { Present } \\
\text { study }\end{array}$ \\
\hline & $\mathrm{PB}$ & IPE 240 & IPE 240 & IPE 240 & IPE 270 & IPE 500 & IPE360 & & $N_{f d}$ & 3 & 3 \\
\hline & $h(\mathrm{~cm})$ & 7.95 & 11.65 & 7.95 & 13.4 & 13.93 & 10.9 & జี & $P S$ & P-2432 & P-2432 \\
\hline & $e(\mathrm{~cm})$ & 7.63 & 7.7 & 7.63 & 8.6 & 11.34 & 8.4 & $\tilde{\Delta}$ & $t_{d}(\mathrm{~cm})$ & 12.5 & 12.5 \\
\hline & $\theta$ & 63.8 & 56.5 & 63.8 & 56.6 & 62.48 & 58.7 & & $t_{s}(\mathrm{~cm})$ & 0.091 & 0.076 \\
\hline
\end{tabular}


transformed net sections and the Vierendeel moments at the bottom fiber of the bottom tee sections is regulated to be smaller than $0.9 F_{y}$. In contrast, we take the concrete shear strength for calculation of required Vierendeel moments into account which leads to the reduction of Vierendeel moments, hence realizing a more economical design method. Then, we regulate the value of reduced Vierendeel moments to be smaller than the ultimate flexural strength of the tee sections determined based on the limit states of plastic moment and lateral-torsional buckling. Finally, the tee sections are checked for combined effect of global and Vierendeel bending.

In order to control the buckling of the web post, Kaveh and Ghafari [9] employed the traditional wedge method, while our model implemented a rapid design aid having taken into account plasticity and strain hardening.

\subsubsection{Second solution of the problem}

The design of the present floor system is repeated by utilizing the St 52.3 steel type and observing the complete set of European H beams and I beams. Both P-2432 and P-3623 Canam deck profiles are used for this solution. The exterior beams are supposed to sustain the wall load applied by ribbon window glazing system with brick spandrels. Foam concrete is selected to cover the structural floor system. The specified live load is reduced in accordance with ASCE/SEI 7-16 [12] and the uniform construction live load is taken into account. All design parameters other than those similar to the first solution are listed in Table 14.
Table 14 Input design parameters of the second solution for the $6 \mathrm{~m} \times 7 \mathrm{~m}$ floor system

\begin{tabular}{lccc}
\hline $\begin{array}{l}\text { Material } \\
\text { Properties }\left(\mathrm{kg} / \mathrm{cm}^{2}\right)\end{array}$ & $\begin{array}{c}\text { Deal } \\
\text { loads }\left(\mathrm{kg} / \mathrm{m}^{2}\right)\end{array}$ & $\begin{array}{c}\text { Live } \\
\text { Loads }\left(\mathrm{kg} / \mathrm{m}^{2}\right)\end{array}$ & $\begin{array}{c}\text { Additional } \\
\text { Loads }(\mathrm{kg} / \mathrm{m})\end{array}$ \\
\hline$F_{y}=3340$ & $W_{d s}=50$ & $W_{l}=300$ & $w_{d g}=0$ \\
$F_{u}=4500$ & $+W_{c}$ & $W_{l c}=98$ & $w_{l g}=0$ \\
& $+W_{s d}$ & & $w_{d e}=750$ \\
& $+W_{b z}$ & & $w_{l e}=0$ \\
\hline
\end{tabular}

The first six floors with least total cost are sorted in an ascending order in Table 15 and the convergence history for the optimal solution is plotted in Fig. 10. A single observation to emerge from the data comparison is that implementation of multiple deck profiles appears to be effective for reducing the total cost of the floor. If we eliminate the P-3623 deck profile, a $5 \%$ increase will be observed in the final cost of the floor.

The correlation between the $1^{\text {st }}$ and the $5^{\text {th }}$ deck is noteworthy as it highlights the effect of floor division numbers (Table 15). The two floors share identical deck properties but their numbers of interior beams are different. Increasing single number of interior beams for the 1st floor increases the cost of interior beams directly and also leads to a rise in the cost of supporting girders. Overall, this seemingly small variation, could improve the total cost by about $9.1 \%$ that defines the final solution to the current design problem.

Table 15 Basic variables of the second solution for the $6 \mathrm{~m} \times 7 \mathrm{~m}$ floor system

\begin{tabular}{|c|c|c|c|c|c|c|c|c|}
\hline \multirow[b]{2}{*}{ Initial sections } & \multicolumn{4}{|c|}{ Material distributions } & \multicolumn{4}{|c|}{ Cost distributions $(\$) \&$ [order] } \\
\hline & $N_{f h}$ & Deck profiles & $t_{d}(\mathrm{~cm})$ & $t_{s}(\mathrm{~cm})$ & $N_{f h}$ & Decks & Beams & Floor systems \\
\hline $\begin{array}{l}\text { IPE AA } 220 \\
\text { IPE AA } 220 \\
\text { IPE AA } 220\end{array}$ & 3 & P-3623 & 0.076 & 10 & 3 & $1665[1]$ & $2515[1]$ & $4185[1]$ \\
\hline $\begin{array}{l}\text { IPE AA } 220 \\
\text { IPE AA } 220 \\
\text { IPE AA } 240\end{array}$ & 0 & P-3623 & 0.091 & 10 & 3 & $1815[3]$ & $2555[2]$ & $4370[2]$ \\
\hline $\begin{array}{l}\text { IPE AA } 220 \\
\text { IPE AA } 220 \\
\text { IPE AA } 240\end{array}$ & 0 & P-2432 & 0.076 & 12.5 & 3 & $1825[4]$ & $2568[3]$ & $4395[3]$ \\
\hline $\begin{array}{l}\text { IPE AA } 220 \\
\text { IPE AA } 220 \\
\text { IPE AA } 240\end{array}$ & 0 & P-2432 & 0.091 & 12.5 & 3 & $1990[5]$ & $2570[4]$ & $4560[4]$ \\
\hline $\begin{array}{l}\text { IPE AA } 220 \\
\text { IPE AA } 220 \\
\text { IPE AA } 240\end{array}$ & 0 & P-3623 & 0.076 & 10 & 4 & $1670[2]$ & $2935[6]$ & $4605[5]$ \\
\hline $\begin{array}{l}\text { IPE AA } 220 \\
\text { IPE AA } 220 \\
\text { IPE AA } 240\end{array}$ & 0 & P-2432 & 0.091 & 14 & 3 & $2075[6]$ & $2570[5]$ & $4645[6]$ \\
\hline
\end{tabular}




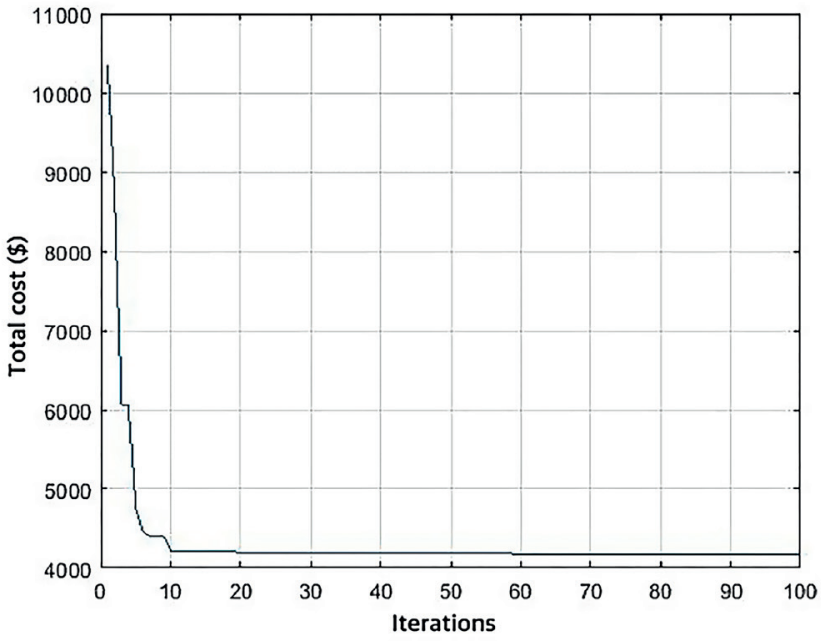

Fig. 10 The cost history graph for the $6 \mathrm{~m} \times 7 \mathrm{~m}$ floor system

\section{Summary and conclusions}

Due to the light weight and complicated design method of castellated beams, our computerized cost optimization program optimized the floor systems supported by castellated beams in a technically meticulous manner. Performance of the program has been outlined in great detail encompassing the efficient VPS algorithm and several cost-reduction practices, as well as an accurate and comprehensive design method considering 31 applicable constraints.

Optimizing various floors taken from the literature revealed indisputable evidence that the proposed program meets the economic requirements, ensures safety and structural performance, and provides a reliable and cost-effective design tool for practical purposes. This verification has presented positive outcomes that advance the current knowledge. A number of salient concluding remarks can be drawn as follows:

- For long floor systems e.g. $15 \mathrm{~m}(50 \mathrm{ft})$ the program as compared to traditional classical design method is able to effectively reduce the cost of the complete floor by about $20 \%$.

- For medium span length e.g. $6 \mathrm{~m}$ (c. $20 \mathrm{ft}$ ) the program as compared to other non-deterministic optimization models could reduce the final cost up to $17 \%$.

- The program in some instances was able to reduce the structural depth of the floor system more than $20 \%$.

- For attaining optimum cost, simultaneous optimization of the deck-slab and supporting steel beams is vital. This treatment in some instances of long floor systems could reduce the final price up to $12 \%$.

- Increasing the number of deck profiles efficiently improves the solutions. We could manage to improve the solutions by about $10 \%$ by means of adding a single deck profile.
- If the cost function is adjusted to be a function of the number of floor divisions, finding the optimum value of floor divisions could reduce the cost significantly. We were able to reduce the final cost up to $9 \%$ by using the same deck profile but the optimum number of floor divisions.

- Implementation of cost saving strategies like considering partial composite action, infilling web openings and specifying camber could successfully prevent an increase in the final price of the floor system.

- The proposed program is able to determine the optimal cutting pattern for individual castellated beam.

- As a result of investigating 150 optimization problems, the optimal cutting pattern for fabrication of castellated beams described by non-dimensional parameters of $d_{g} / d, s / \mathrm{h}$, and $\theta$ appears to be $1.5,2.6$ and $55.5^{\circ}$ respectively. These values for commercial Litzka and Anglo-Saxon cutting patterns are 1.5, 3, $63.5^{\circ}$ and $1.5,2.16,60^{\circ}$ respectively.

Future works should mainly cover the development of additional features, enabling the program to compare different conditions in order to find the optimum state, for instances:

- Comparison between a variety of stud anchors and channel anchors considering both economical and strength issues.

- Comparison between a wide spectrum of fractions of composite actions.

- Comparison within the broad range of material properties of steel and concrete components.

- Reinforcing the program such that the user could arbitrarily utilize various deck profiles.

- Inclusion of slab reinforcements into the optimization procedure.

- Enabling the program to specify asymmetric sections for composite application of castellated beams.

- Comparison between two conditions of deck ribs perpendicular to edge beams and deck ribs perpendicular to girders from both economical and strength aspects.

- Conduct a similar study by utilizing the cellular beams and comparing the results with the current study.

- Developing the program with a view to facilitate the optimization of asymmetrical floor layouts.

- Conducting a similar study by exploring multi-bay floor systems for real simulation of reciprocal effects of neighboring bays and proposing a rational method for accurate simulation of the effect of the adjacent bays. 
- Comparing different dimensions of bays in principal directions of the multi-bay floor system from both strength and economical aspects.

- Comparing different classifications of beam to column connections, namely simple, PR and FR.

It is observed that we cannot achieve the optimum solution without the integrated optimization of the main constituents of steel-concrete composite floor systems. This

\section{References}

[1] Kaveh, A., Ahangaran, M. "Discrete cost optimization of composite floor system using social harmony search model", Applied Soft Computing, 12(1), pp. 372-381, 2012.

https://doi.org/10.1016/j.asoc.2011.08.035

[2] Fares, S. S., Coulson, J., Dinehart, D. W. "Design Guide 31: Castellated and Cellular Beam Design", AISC, Chicago, IL, USA, 2016.

[3] Kaveh, A., Shokohi, F. "Cost optimization of end-filled castellated beams using meta-heuristic algorithms", International Journal of Optimization in Civil Engineering, 5(3), pp. 333-354, 2015. [online] Available at: http://ijoce.iust.ac.ir/article-1-219-en.html

[4] ANSI "ANSI/AISC 360-16 Specification for Structural Steel Buildings", American Institute of Steel Construction, Washington, DC, USA, 2016. [online] Available at: https://www.aisc.org/ Specification-for-Structural-Steel-Buildings-ANSIAISC-360-16-1

[5] Adeli, H., Kim, H. "Cost optimization of composite floors using neural dynamics model", Communications in Numerical Methods in Engineering, 17(11), pp. 771-787, 2001.

https://doi.org/10.1002/cnm.448

[6] Klanšek, U., Kravanja, S. "Cost Optimization of Composite I Beam Floor System", American Journal of Applied Sciences, 5(1), pp. 7-17, 2007.

https://doi.org/https://doi.org/10.3844/ajassp.2008.7.17

[7] Poitras, G., Lefrançois, G., Cormier, G. "Optimization of steel floor systems using particle swarm optimization", Journal of Constructional Steel Research, 67(8), pp. 1225-1231, 2011. https://doi.org/10.1016/j.jcsr.2011.02.016

[8] Tsavdaridis, K. D., D'Mello C. "Optimisation of novel elliptically-based web opening shapes of perforated steel beams", Journal of Constructional Steel Research, 76, pp. 39-53, 2012. https://doi.org/10.1016/j.jcsr.2012.03.026

[9] Kaveh, A., Ghafari, M. H. "Optimum design of steel floor system: Effect of floor division number, deck thickness and castellated beams", Structural Engineering and Mechanics, 59(5), pp. 933950, 2016.

https://doi.org/10.12989/sem.2016.59.5.933

[10] Blodgett, O. W. "Design of Welded Structures", James F. Lincoln Arc Welding Foundation, Cleveland, OH, USA, 1966. [online] Available at: https://www.academia.edu/30175576/Design_of Welded_Structures_Omer_W_Blodgett

[11] Aglan, A. A., Redwood, R. G. "Web buckling in castellated beams", Proceedings of the Institution of Civil Engineers, 57(2), pp. $307-320,1974$

https://doi.org/10.1680/iicep.1974.4059 finding seems to show that for attaining the synergy benefits, the merger of the optimal cost design of steel frames with composite floor systems is an essential approach. Hence for the purpose of the further development of the structural optimization into practice, future work will involve proposing a robust optimization program for simultaneous optimization of real size steel frames with the steel-concrete composite floor system.

[12] ASCE "ASCE/SEI 7-16 Minimum Design Loads and Associated Criteria for Buildings and Other Structures", American Society of Civil Engineers, New York, NY, USA, 2016. https://doi.org/10.1061/9780784414248

[13] Benitez, M. A., Darwin, D., Donahey, R. C. "Deflections of Composite Beams with Web Openings", Journal of Structural Engineering, 124(10), pp. 1139-1147, 1998. https://doi.org/10.1061/(ASCE)0733-9445(1998)124:10(1139)

[14] Roll, F. "Effects of Differential Shrinkage and Creep on a Composite Steel-Concrete Structure", ACI Symposium Publication, 27, pp. 187-214, 1971.

[15] Downey, E. W. "Specifying Camber", [pdf] Steelwise - Modern Steel Constructions, 2006. Available at: https://www.aisc.org/globalassets/modern-steel/steelwise/30755 steelwise_camber.pdf

[16] West, M., Fisher, A. "Design Guide 3: Serviceability Design Considerations for Steel Buildings", AISC, Chicago, IL, USA, 2003.

[17] Murray, T. M., Allen, D. E., Ungar, E. E. "Design Guide 11: Vibrations of Steel-Framed Structural Systems Due to Human Activity", AISC, Chicago, IL, USA, 1997.

[18] Murray, T. M. "Building Floor Vibrations", [pdf] In: Engineering Journal, Proceedings of the AISC National Steel Construction Conference, Washington, DC, USA, 1991, pp. 102-109. Available at: https:/www.aisc.org/globalassets/aisc/awards/tr-higgins/pastwinners/building-floor-vibrations.pdf

[19] Naeim, F. "Design Practice to Prevent Floor Vibrations", Structural Steel Educational Council, Walnut Creek, CA, USA, 1991.

[20] CANAM Buildings "Steel Deck", 2006. [online] Available at: https:/www.canam-construction.com/en/construction-products/ steel-deck/? [14 November 2020]

[21] Siarry, P. "Metaheuristics", Springer, Cham, Switzerland, 2016. https://doi.org/10.1007/978-3-319-45403-0

[22] Kaveh, A., Mahdavi, V. R. "Colliding Bodies Optimization, Extensions and Applications", Springer, Cham, Switzerland, 2015. https://doi.org/10.1007/978-3-319-19659-6

[23] Kaveh, A., Ilchi Ghazaan, M. "Vibrating particles system algorithm for truss optimization with multiple natural frequency constraints", Acta Mechanica, 228, pp. 307-322, 2017. https://doi.org/10.1007/s00707-016-1725-z

[24] Chopra, A. K. "Dynamics of Structures, Theory and Applications to Earthquake Engineering", Pearson Education, Boston, MA, USA, 1995. [online] Available at: https://www.researchgate.net/ publication/337936833 Dynamics-of-structures

[25] Clough, R. W., Penzien, J. "Dynamics of Structures", Computers \& Structures, Inc., Berkeley, CA, USA, 1995. 
[26] Kaveh, A., Talatahari, S. "A novel heuristic optimization method: charged system search", Acta Mechanica, 213, pp. 267-289, 2010. https://doi.org/10.1007/s00707-009-0270-4

[27] Kaveh, A., Ilchi Ghazaan, M. "A new meta-heuristic algorithm: vibrating particles system", Scientia Iranica, 24(2), pp. 551-566, 2017. https://doi.org/10.24200/sci.2017.2417
[28] AISC "Steel Construction Manual", 15th ed., American Institute of Steel Construction, Chicago, IL, USA, 2017.

[29] CISC "Handbook of Steel Construction", 11th ed., Canadian Institute of Steel Construction, Markham, ON, Canada, 2016.

[30] Salmon, C.G., Johnson, J. E., Malhas, F. A. "Steel Structures, Design and Behavior", Pearson, Upper Saddle River, NJ, USA, 2009. 